Article

\title{
Supplier Risk Assessment Based on Best-Worst Method and K-Means Clustering: A Case Study
}

\author{
Merve Er Kara * (10) and Seniye Ümit Oktay Fırat \\ Department of Industrial Engineering, Faculty of Engineering, Marmara University, 34722 Istanbul, Turkey; \\ suofirat@marmara.edu.tr \\ * Correspondence: merve.er@marmara.edu.tr; Tel.: +90-216-348-0292
}

Received: 18 January 2018; Accepted: 28 March 2018; Published: 4 April 2018

\begin{abstract}
Supplier evaluation and selection is one of the most critical strategic decisions for developing a competitive and sustainable organization. Companies have to consider supplier related risks and threats in their purchasing decisions. In today's competitive and risky business environment, it is very important to work with reliable suppliers. This study proposes a clustering based approach to group suppliers based on their risk profile. Suppliers of a company in the heavy-machinery sector are assessed based on 17 qualitative and quantitative risk types. The weights of the criteria are determined by using the Best-Worst method. Four factors are extracted by applying Factor Analysis to the supplier risk data. Then k-means clustering algorithm is applied to group core suppliers of the company based on the four risk factors. Three clusters are created with different risk exposure levels. The interpretation of the results provides insights for risk management actions and supplier development programs to mitigate supplier risk.
\end{abstract}

Keywords: cluster analysis; corporate sustainability; risk assessment; supplier evaluation and selection; supply risk

\section{Introduction}

Procurement and purchasing are vital functions that have strategic importance for the success of an organization. Generally, a company spends almost $60 \%$ of its total sales on purchasing raw materials, assemblies, components, and parts [1]. Hence, evaluation and selection of suppliers is one of the most critical strategic decisions for developing a competitive and sustainable organization [2]. Nowadays, supplier selection problem incorporates approaches from different disciplines and goes beyond traditional cost minimization and profit maximization objectives [3-5]. Especially a growing number of researchers started to incorporate risk minimization objective into this problem [6-9]. Supplier-related risks are among the most frequently discussed risks in the supply chain (SC) literature $[10,11]$. Supply risk is an umbrella term that includes the factors affecting the inbound flow of goods or services; e.g., supplier failures, late deliveries, quality problems, financial instability of suppliers, and poor supplier relationship management strategies [10,12]. Supplier-related risks such as disruption of production, customer dissatisfaction, financial losses, loss of sales, damages to corporate image, and bankruptcy may have serious consequences for companies and their entire SC networks [13]. In today's competitive and risky business environment, it is very important to work with reliable suppliers for the sustainability of business. Therefore, companies have to consider supplier-related risks and threats in their purchasing decisions. Supplier risk measures have to be defined and incorporated into the supplier evaluation and selection process to mitigate supply risk $[1,14,15]$.

Instead of selecting one supplier, some researchers proposed to generate supplier groups by considering suppliers' different attributes or business behaviors [16-19]. This approach provides the 
following advantages [20,21]; (i) elimination of suppliers that do not provide the desired specifications; (ii) obtaining manageable smaller and homogeneous supplier groups; (iii) development of specific supplier development programs for different supplier clusters. However, there are very few studies in this area, and to the best of authors' knowledge there is not a research that applies cluster analysis to group suppliers based on their risk characteristics and behaviors. Therefore, this study focuses on supplier-related risks and aims to cluster suppliers based on their risk profile. Various quantitative and qualitative approaches have been proposed for supplier risk assessment problems in the literature [22-24]. Clustering approaches allow for different groups of alternative suppliers with similar supply risk levels. These supplier clusters give the opportunity to produce specific supplier development programs and risk mitigation efforts for different clusters. In addition, a limited number of studies in the supplier evaluation and selection literature have examined supplier risks with a multi-dimensional approach [25-27]. This study also contributes to this research gap by evaluating suppliers based on different dimensions of supply risk.

A company that operates in the heavy-machinery industry was selected for the case study. The core suppliers of the company were assessed based on four quantitative and 13 qualitative criteria related with different risk types. The values of the qualitative criteria were determined by subjective evaluations of three decision makers. These decision makers have different levels of knowledge and experience about different attributes of suppliers. Hence, different weights were assigned to the grades of decision makers for different criteria. Supplier evaluation criteria were also weighted by using the Best-Worst method (BWM), which is a new multi-criteria decision making method proposed by Jafar Rezaei in 2015 [28].

Four factors were extracted by applying Factor Analysis to the supplier risk data. Then, k-means clustering algorithm [29] was applied to group core suppliers of the company based on the generated four risk factors, and three clusters were created with different risk exposure levels. To the best of our knowledge, this is the first study that applies cluster analysis to group suppliers based on their risk profile. The results of the clustering algorithm were used to evaluate the risk characteristics of the suppliers in different clusters. The interpretation of the results provides valuable insights into selecting risk management actions to mitigate supplier-related risks. Suppliers with a high-risk profile can be eliminated or supplier development programs can be developed based on the results of the analysis.

The remainder of the paper is organized as follows: Section 2 presents different clustering approaches in the supplier evaluation and selection literature. Some of the risk criteria that are used to evaluate and select suppliers are summarized in Section 3. Then, the proposed clustering based supplier risk assessment approach is explained in detail in Section 4. The results of BWM, factor analysis and clustering algorithm are given. Finally, the results of the analysis are discussed and conclusions are presented in Section 5.

\section{Clustering Approaches in Supplier Evaluation and Selection}

Supplier evaluation and selection is a complex, risky and hard multi-criteria decision-making (MCDM) problem that provides a framework for comparing and selecting suppliers [5,30]. The aim of this process is to evaluate suppliers based on some predetermined quantitative and qualitative criteria related with the requirements of the company. The literature on supplier evaluation and selection is rich of studies that proposed various individual and integrated approaches for this problem [3,31,32]. Some of these methods can be listed as follows: Analytical Hierarchy Process (AHP) [33,34], Analytic Network Process (ANP) [25,30], Data Envelopment Analysis (DEA) [35], Technique for Order Performance by Similarity to Ideal Solution (TOPSIS) [35], Mathematical Programming Models such as linear programming, integer programming, multi-objective programming and goal programming [7,9,33], Neural Network (NN) [17], and Fuzzy Logic [5,36,37].

Many large companies work with hundreds of suppliers to provide raw materials, parts, sub-assemblies and other components. Even some large-scale enterprises have thousands of suppliers [16]. Therefore, some researchers proposed to generate supplier groups instead of selecting one supplier [16-21]. 
There are two types of researches for grouping suppliers in the literature: (i) cluster analysis, and (ii) segmentation. Both of them aim to identify a group of alternative suppliers or eliminate suppliers according to predetermined criteria. Categorization of suppliers based on different attributes provides the following advantages for companies:

(1) Created supplier segments can be used to eliminate supplier groups that do not provide the desired specifications. Hence, it helps to obtain manageable smaller and homogeneous supplier groups, reduce the number of alternatives, and increase the simplicity and flexibility of the supplier selection process $[20,21,38,39]$.

(2) It is helpful when there are very large number of supplier combinations for different parts of a product [20].

(3) It provides the opportunity of selecting a group of suppliers when the company prefers to select more than one supplier for various reasons such as capacity constraints of suppliers [19].

(4) Providing alternative suppliers helps to act quickly in the case of unforeseen interruptions in the supply of raw materials. Existence of a qualified vendor pool allows companies to substitute a disrupted supplier easily and quickly with a new supplier, and increases the efficiency of the supplier risk management process.

(5) It provides the opportunity to develop specific plans and strategies for different supplier groups to develop successful supplier management programs, enhance supplier relationship management, improve supplier performance management systems, and develop effective risk management systems [40].

(6) In recent years, the variety of supplier evaluation and selection criteria have increased and it is very hard to find meaningful patterns within such a complex structure. Clustering is a powerful and efficient tool to learn about complex and huge data sets [29,41].

Clustering is an exploratory data analysis technique and tries to form homogenous subgroups by partitioning observations in a data set based on the similarity in their characteristics [42]. Similarity is usually measured by distance measures. There is a myriad of clustering algorithms in the literature. Jain [41] has summarized well-known clustering methods. One of the most popular clustering algorithms is k-means clustering [29,42]. K-means algorithm clusters observations into k groups where $\mathrm{k}$ is an input parameter. It assigns observations into clusters based on their distance to the mean of the clusters iteratively. Clustering algorithms have been used in various areas including marketing research, fraud detection, and analysis of healthcare data [41-43]. However, there are very few studies on the use of cluster analysis for grouping suppliers [16-21].

Zhang et al. [16] categorized suppliers based on suppliers' business behaviors by using k-means type subspace clustering algorithm, Feature Weighting K-means (FW-KMeans). Their data-driven method tries to derive suppliers' business behaviors by using a large volume of business transactions data. Ha and Krishnan [17] proposed a hybrid model incorporating AHP, DEA and NN for supplier evaluation. A combined supplier score was calculated by considering both qualitative and quantitative factors that affect the performance of the SC. Then self-organizing map (SOM) which is a neural clustering method was applied by accounting only quantitative criteria to find homogenous supplier clusters and create a supplier map.

Che and Wang [20] developed a hybrid approach, KSACPSO, based on K-means, simulated annealing (SA) algorithm, convergence factor particle swarm optimization and the Taguchi method to discriminate types of part suppliers based on product cost, quality and procurement time. They also used analysis of variance (ANOVA) and Scheffe's multiple comparison to compare the convergence values of six algorithms and find the optimal supplier clusters. Che [44] proposed two optimization models for supplier clustering and selection respectively. Supplier clusters were determined by using the customer demand attributes such as production cost, product quality and production time. The two mathematical models were solved by a two-phase method. Phase 1 integrates k-means and SA algorithm with the Taguchi method, and Phase 2 uses AHP to weight each factor and then uses 
SA algorithm with the Taguchi method. Şahin and Supçiller [39] used AHP to identify the weights of the supplier selection criteria and then ranked the suppliers according to the weighted scores using TOPSIS. These suppliers were then clustered using k-means method into four clusters.

Some of the researchers used fuzzy values to show the preferences of decision makers, and applied fuzzy clustering. Bottani and Rizzi [38] integrated AHP, cluster analysis and fuzzy logic to cluster and rank suppliers and purchased items. They grouped suppliers by performing cluster analysis and then selected the best supplier cluster by applying AHP. Khaleie et al. [21] proposed an intuitionist fuzzy clustering based method for supplier selection based on intuitionistic fuzzy values for decision makers' opinions. They used four main criteria (quality, price/cost, delivery, and company and technology ability) and a total of eight sub-criteria. Haghighi et al. [18] used Fuzzy Linguistic Preference Relations (LinPreRa)-based AHP to weigh the supplier selection criteria and then used fuzzy c-means algorithm twice to cluster suppliers based on capabilities and willingness criteria. The results of the clustering algorithm was used to segment suppliers. Heidarzade et al. [19] used interval type-2 fuzzy values to represent decision makers' preferences and proposed a hierarchical clustering-based method with a new distance formula for supplier selection problem.

There are also studies that focus on supplier segmentation by computing their aggregated scores $[18,23,40,45,46]$. Supplier segmentation aims to classify suppliers into different groups generally with the aim of building different supplier management and development strategies and programs [40]. Suppliers are commonly grouped into four segments based on two dimensions [45]. Matook et al. [46] performed factor analysis on the risk rating data of 17 suppliers. Risk ratings were gathered through questionnaire and expert discussions. Two factors were extracted from seven different risk types. The factor scores of the suppliers were plotted in two dimensions, and six supplier groups were identified by using this factor plot. Rezaei and Ortt [45] combined different supplier typologies based on the capabilities and willingness of suppliers for cooperation. They proposed fuzzy AHP to segment suppliers. In a later study, Rezaei et al. [40] proposed a new MCDM method, BWM, for supplier segmentation.

\section{Supply Risk Issue in Supplier Evaluation and Selection}

The quality of the supplier evaluation and selection process highly depends on the effective selection of the criteria [30,47]. A myriad of quantitative and qualitative criteria have been proposed in the literature including cost, quality, delivery performance, manufacturing capability, research and development (R\&D), and reputation $[3,25,37,48]$. Supplier evaluation criteria should be appropriate with the requirements of the company and applicable to all suppliers that will be evaluated [39]. The importance of the criteria varies according to business priorities and strategies of the focal company [31]. According to the literature review of Ho et al. [49] on 78 articles between 2000 and 2008, the most popular criteria are as follows: quality, delivery, price/cost, manufacturing capability, service, management, technology, research and development, finance, flexibility, reputation, relationship, risk, and safety and environment. Chen [35] gave a table of some important criteria including quality, deliver on time, historical performance, guarantee and compensation, technical capability, geographic location, packing ability, and communication system. Punniyamoorthy et al. [50] used 46 sub-criteria under 10 main categories for supplier selection: management and organization, quality, technical capability, production facilities and capacities, financial position, delivery, service, relationship, safety and environment concern, and cost. They made a survey to 151 respondents to determine the relative weights of these criteria.

In recent years, researchers and practitioners started to integrate new dimensions such as sustainability, green practices and risk into the supplier evaluation process [3,5,9,11]. Especially, the use of intangible and qualitative factors has increased: e.g., supplier relationships, reputation of the company, risk, level of trust, communication, and corporate social responsibility $[4,15,30,50]$. Some of the factors that lead to the change in the supplier evaluation and selection criteria are as follows [31,47]: (i) Complexity and risks in SC networks; (ii) High dependency on suppliers; 
(iii) Increased globalization and offshoring; (iv) Growing awareness of customers on sustainability related issues; (v) Changes in customer requirements and preferences; and (vi) Rise in regulations. Rapid depletion of natural resources, environmental legislations, government regulations, and increasing awareness on sustainability drive companies to consider sustainability issues more in their supplier selection processes. Economic, environmental, and social dimensions of sustainability must be considered in evaluating and selecting suppliers [4,31]. However, there are a limited number of researchers that address sustainability issue in their study [9,30,34]. Er Kara et al. [4] made a literature review on the indicators that are used to measure the sustainability of suppliers. They classified various sustainable supplier selection criteria under the three dimensions of sustainability (e.g., environmental competencies, resource consumption, waste management, corporate social responsibility, strategic cooperation level). Table 1 gives some of the traditional and emerging criteria that are used in the supplier evaluation and selection literature. Increasing awareness on sustainability and the rising risk exposure levels in the business environment drive companies to consider risk factors and the three pillars of sustainability in their supplier evaluation and selection process $[3,4,9,34]$.

Table 1. Some of the traditional and emerging supplier evaluation and selection criteria from the literature.

\begin{tabular}{llll}
\hline \multicolumn{1}{c}{ Traditional Criteria } & \multicolumn{1}{c}{ Reference(s) } & \multicolumn{1}{c}{ Emerging Criteria } & \multicolumn{1}{c}{ Reference(s) } \\
\hline Price/cost & {$[17,18,20,21,34-36,49]$} & Risk & {$[6-9,15,22,25-27,36,51-55]$} \\
\hline Quality & {$[17-21,25,34-37,44,49,50,56]$} & $\begin{array}{l}\text { Environmental competencies and } \\
\text { green practices }\end{array}$ & {$[3-5,9,30,31,34,37,47]$} \\
\hline Delivery performance & {$[17-19,21,25,35-37,49,50,56]$} & $\begin{array}{l}\text { Human rights \& Labor health and } \\
\text { safety }\end{array}$ & {$[4,9,23,34]$} \\
\hline $\begin{array}{l}\text { Manufacturing/technological } \\
\text { capability }\end{array}$ & {$[19,21,34-36,40,49,50,56,57]$} & Corporate social responsibility & {$[4,31,56]$} \\
\hline Reputation & {$[21,31,37,40,57]$} & $\begin{array}{l}\text { Data administration \& } \\
\text { Information Technology (IT) level }\end{array}$ & {$[17,21]$} \\
\hline Performance history & {$[17,36,56]$} & Information disclosure & {$[34]$} \\
\hline
\end{tabular}

Companies started to consider supplier related risks and threats in their purchasing decisions in order to survive in today's highly complex, dynamic and risky business environment $[1,15,58]$. Some past disruptive events have shown that even a small risk event in a sub-tier supplier may cause serious consequences for the entire SC [59]. Therefore, supplier risk measures have to be defined and incorporated into the supplier selection process to cope with supplier related uncertainties and threats $[30,33,58]$. Supply risk is a multidimensional concept and covers various different risk factors such as failure of suppliers, disruption/loss of a supplier, non-conforming materials or parts, late deliveries, and communication problems with suppliers [10].

There are a lot of studies that incorporate risk issue into their mathematical programming model for supplier selection [7-9,51,60]. Most of the studies incorporate risk by adding a risk-based goal and one or a few variables that represent suppliers' risk attributes. Hamdi et al. [7] developed two mixed integer programs for supplier selection and order allocation problem under local supplier disruption risk. The first model aims to identify the optimal order quantities for each supplier to maximize the expected profit. The second model considers a risk-averse decision maker who aims to minimize the operational loss. Vahidi et al. [9] proposed a two-stage mixed possibilistic-stochastic programming approach with a mixed sustainability-resilience objective function to formulate sustainable supplier selection and order allocation problem under operational and disruption risks. Sawik [51] formulated a single-period supplier selection and order allocation problem in make-to-order environment with risk as a stochastic single or bi-objective mixed integer problem. The model aims to minimize the total cost and reduce the impact of the delay risk. Value-at-risk $(\mathrm{VaR})$ and conditional value-at-risk $(\mathrm{CVaR})$ measures were used to control delayed supply risk. In a later study, Sawik [60] proposed a stochastic mixed integer programming approach for the joint supplier selection and scheduling of customer orders in the presence of SC disruption risks. The results showed that supplier reliability is a 
key parameter for supplier selection. Patra and Mondal [8] developed three different supplier selection models in crisp and fuzzy environments by considering two objective functions: profit maximization and risk minimization. They also applied a sensitivity analysis to investigate the effect of different risk values on the objective function.

Hong and Lee [52] proposed a decision support system (DSS) to model risks for the procurement processes in the presence of spot market. A Monte Carlo simulation algorithm called the Expected Profit-Supply at Risk (SaR) was used to evaluate the performance of each supplier and quantify their risks for supplier selection and order allocation. They classified suppliers into three groups by using expected profit and SaR: preferred suppliers, approved suppliers and avoided suppliers. Lee [61] studied on determining the optimal number of suppliers and considered semi-super events that can disrupt all suppliers in a specific geographical location. Knemeyer et al. [53] proposed the addition of "catastrophic risk exposure" criteria into the supplier selection problem as an alternative countermeasure to cope with this type of risks. Kuo et al. [30] used risk assessment and risk management as one of 17 criteria that are used for evaluating green suppliers in an electronics company. Wang et al. [58] incorporated risk reduction and responsiveness criteria into their supplier selection framework for a resilient construction SC.

There are very few articles that consider supply risk in the supplier evaluation process with a multi-dimensional approach [6,15,36,62]. Kull and Talluri [33] proposed a model that integrates AHP and goal programming for supplier selection in the presence of supply risk and product life cycle considerations. They considered the following failure events: delivery, cost, quality, flexibility, and general confidence failures. Pairwise comparisons of risk dimensions were performed with respect to both their relative likelihood and impact on business performance. Lee [36] proposed a fuzzy AHP model that incorporates benefits, opportunities, costs, and risks to evaluate suppliers based on different aspects. Multiple factors that positively or negatively affect the success of the relationship were considered. The sub-criteria in the risk category are supply constraint, buyer-supplier constraint and supplier's profile. PrasannaVenkatesan and Goh [15] ranked a set of suppliers by using fuzzy AHP and fuzzy PROMETHEE, and then applied multi-objective particle swarm optimization algorithm to obtain a set of Pareto-optimal solutions based on cost, customer service, and risk criteria. The sub-criteria under risk category are output flexibility, contractual commitments, labor issues, visibility, geographical location, and political/economic stability. Fang et al. [6] proposed a probability based multi-criteria optimization model including both risk criteria and supplier performance in order to examine the tradeoff between cost and risk factors. They used VaR for the evaluation of operational risks such as defects, late delivery and uncertain demand. They also used CVaR for the assessment of supply disruptions caused by natural and man-made disasters. Amorim et al. [62] proposed a stochastic mixed-integer programming model for supplier selection in the processed food industry. They considered the uncertainties in supply; uncertainty in available quantity and lead-time. Their model focuses on sourcing of perishable raw materials and aims to maximize profit and minimize risk of low customer service level. Wu and Olson [63] used chance-constrained programming, DEA and multi-objective programming models for vendor selection in an uncertain environment. Different risk embedded attributes were modeled with probability distributions of costs, acceptance failure, and late delivery.

A limited number of researchers used both qualitative and quantitative risk criteria in their study [22,26,37,54,57]. Nekooie et al. [25] took into account both high probability-low impact and low probability-high impact supply disruptions in the supplier selection problem. The most important qualitative risk factors are determined by using ANP as excessive handling due to border crossing or change in transportation modes, data information security, and cost uncertainty, respectively. They also incorporated two quantitative criteria into their mathematical model; delay and defect rate. Chou and Chang [57] presented a strategy-aligned fuzzy SMART approach by using both qualitative and quantitative criteria for supplier selection. A final decision maker incorporates the supply risks of suppliers in his/her assessments by using a risk coefficient. Wu et al. [26] proposed a 
fuzzy multi-objective programming model for supplier selection considering risk factors. They used simulated historical data for both quantitative (cost, quality, and logistics) and qualitative (economic environmental factors and vendor ratings) risk factors. Xiao et al. [54] used an integrated approach of fuzzy cognitive map and fuzzy soft set model for supplier selection considering quality risk of the product, service risk, supplier's profile risk, and long-term cooperation risk. Chan and Wang [22] proposed an integrated approach based on AHP and fuzzy set theory for supplier risk assessment to solve supplier selection problem. They used five main risk categories: quality, delivery, cost, manufacturing capacity, and service. Paul [37] used a rule-based fuzzy inference system (FIS) for supplier selection considering relevant criteria for managing supply risks. They identified four quantitative and 14 qualitative selection criteria. Fuzzy input and output variables are used to incorporate risks into the model. Table 2 gives some of the supplier evaluation and selection criteria under risk category in the reviewed articles.

Table 2. Different supplier evaluation and selection criteria under risk category.

\begin{tabular}{|c|c|c|c|}
\hline Risk Criteria & Reference(s) & Risk Criteria & Reference(s) \\
\hline Late delivery & {$[6,14,22,25-27,33,51,63]$} & $\begin{array}{l}\text { Reliability/contractual } \\
\text { commitment risk }\end{array}$ & {$[1,15]$} \\
\hline Cost/price risk & {$[14,22,25,26,33,36,37,63]$} & $\begin{array}{l}\text { Inadequate environmental } \\
\text { controls and programs }\end{array}$ & {$[36,37]$} \\
\hline Operational risk & {$[6,7,9,27,57]$} & $\begin{array}{l}\text { Catastrophic risks/Natural } \\
\text { disasters }\end{array}$ & {$[6,53,61]$} \\
\hline Quality risk & {$[6,14,22,25,26,33,37,54,63]$} & $\begin{array}{l}\text { Risk assessment \& risk } \\
\text { management practices }\end{array}$ & [30] \\
\hline $\begin{array}{l}\text { Bad performance history } \\
\text { and reputation }\end{array}$ & {$[36]$} & Political/economic stability & {$[15,26,37,55]$} \\
\hline Uncertain lead time & [62] & Low customer service level & {$[14,22,26,54,62]$} \\
\hline Manufacturing capacity risk & {$[22,36]$} & Information security & {$[1,25]$} \\
\hline $\begin{array}{l}\text { Production capability and } \\
\text { technology limit }\end{array}$ & {$[36]$} & Capability to solve problems & [14] \\
\hline Flexibility risk & {$[15,33,57]$} & Bargaining power of supplier & {$[36]$} \\
\hline
\end{tabular}

A limited number of researchers explored supplier evaluation and selection problem under a risk management perspective [14,27,37]. Hamdi et al. [1] reviewed and classified 124 papers from 2003 to 2014 related with supplier selection based on Supply Chain Risk Management (SCRM). According to their review, the most frequent risks are reliability risk, variability of customers' requests, risk of sharing information, and quantity discounts, respectively. Chen and Wu [14] examined supplier evaluation and selection as a SCRM problem. They proposed a modified failure mode and effects analysis method to select suppliers by considering potential failure factors in the SC. Similarly, Mavi et al. [27] studied on supplier selection problem in the context of SCRM. They used Shannon entropy for weighting criteria and fuzzy TOPSIS for ranking suppliers. Nine criteria were used to evaluate suppliers; quality, on time delivery, performance history, and six risks including supply, demand, manufacturing, logistics, information, and environmental risks.

Global supplier selection problem is more complex and risky than domestic sourcing. For global supplier selection, Chan and Kumar [55] used fuzzy extended AHP to cope with different criteria such as cost, quality, service performance, and supplier's profile including risk factors. The discussed risk factors are related with political stability, geographical location, economic status, and terrorism. Schoenherr et al. [64] used action research and AHP for an offshore sourcing decision. 17 risk factors were identified through iterative and structured discussions. Some of these risk factors/ performance measures are listed as follows: comply with the standards of American National Standards Institute, product quality, competitor cost, demand risk, logistics risk, wrong partner risk, overseas risk, supplier risk, supplier's supplier management risk, and natural disasters/terrorists. 


\section{Case Study}

\subsection{Problem Definition and Solution Approach}

The case study company is in the heavy machinery sector, and supplies products and services to both domestic and foreign customers. It manufactures machinery and equipment, and also establishes complete turn-key facilities for different industries including mining, cement, defense, work machines, energy, and ship building industries. The company produces highly customized and configured products, and hence, it uses a make-to-order production strategy to be more flexible and responsive to the product variability. Holding stock may be impossible for most of the parts and assemblies because of the high variety in customer orders and high financial value of the parts.

The company has a diverse set of suppliers for different parts and equipment required to produce mills. The performance of suppliers has a huge effect on the performance and sustainability of the company. Supplier evaluation and selection process is based on several traditional criteria in the company. However, they face significant supply risk problems by overlooking supplier-related threats. Supply risk should be decreased at the beginning of the procurement function by eliminating unreliable and risky suppliers. This can be achieved by considering risk levels of the suppliers in the supplier selection process. The aim of the case study is to propose a clustering-based model for supplier evaluation and selection problem considering supply risk.

The main and best-selling product of the company is mills. In addition, the production of mills requires working with a higher number of suppliers. Therefore, the suppliers of the core parts of a mill are selected for the cluster analysis. Most of the suppliers of the company are national firms. There are small, medium and large-sized suppliers. Totally 72 key suppliers are identified as the most critical suppliers of the company, and selected for the analysis. Among these suppliers, 69 are domestic and three are overseas companies. Some of the selected suppliers produce different products. This is one of the limitations of the case study due to the total number of suppliers of the company.

First, a set of supplier evaluation and selection criteria is determined through literature review. Supplier evaluation and management criteria vary depending on the strategy, sector, risk attitude, and the needs of the organization [55]. Therefore, several iterative and structured meetings and discussions are performed with managers and purchasing staff in the case study company in order to determine the criteria that will be used in the analysis. Finally, four quantitative and thirteen qualitative criteria are identified under eight risk dimensions. The weights of the risk criteria are determined by using the BWM that is proposed by Jafar Rezaei $[28,65]$. First, the best (most important) and worst (least important) criteria are selected among a set of criteria. Then, the decision maker evaluates the preference of the best risk criterion and worst criterion over the other risk criteria respectively. Figure 1 represents the comparison of the best and the worst criteria with the other criteria (reference comparisons).

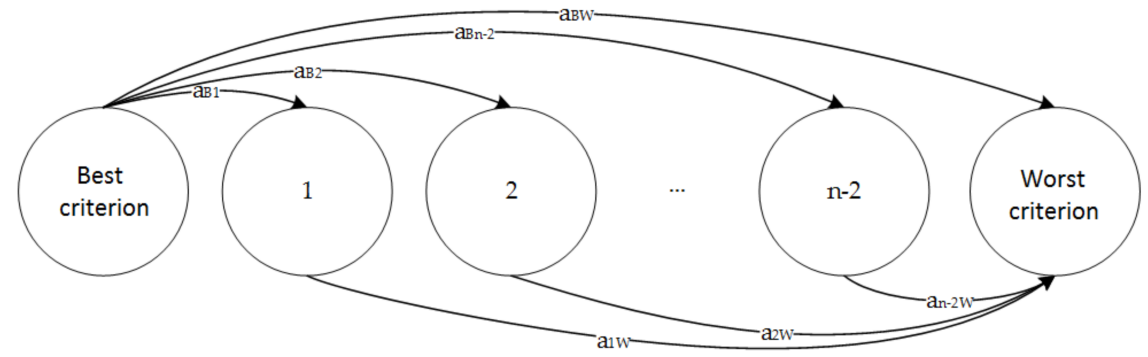

Figure 1. Comparison of the best and worst criteria with the other criteria (adapted from [28]).

The decision maker determines the preference of the best risk criterion over all the other risk criteria using a nine-point pairwise comparison scale. It generates the Best-to-others vector for each decision maker: 


$$
A_{B}=\left(a_{B 1}, a_{B 2}, \ldots, a_{B n}\right),
$$

where $a_{B j}$ represents the preference of the best criterion B over criterion $j$. The value of $a_{B j}$ will be equal to 1 if criterion $\mathrm{j}$ is the best criterion $\left(a_{B B}=1\right)$.

Then the decision maker determines the preference of all the other criteria over the worst criterion using the same scale. This generates the Others-to-worst vector for each decision maker:

$$
A_{W}=\left(a_{1 W}, a_{2 W}, \ldots, a_{n W}\right)^{T},
$$

where $a_{j W}$ represents the preference of criterion $j$ over the worst criterion $W$. The value of $a_{j W}$ will be equal to 1 if criterion $j$ is the worst criterion $\left(a_{W W}=1\right)$. Due to the reciprocal property of the pairwise comparison matrix, totally $(2 n-3)$ pairwise comparisons are conducted by each decision maker.

The next step is calculating the optimal weights $\left(w_{1}^{*}, w_{2}^{*}, \ldots, w_{n}^{*}\right)$ by using the evaluations of the decision makers. The optimal weights for the risk criteria satisfy the following conditions: (i) $w_{B} / w_{j}=a_{B j}$, and (ii) $w_{j} / w_{W}=a_{j W}$ [59]. Therefore, we need to minimize the maximum absolute differences $\left|\frac{w_{B}}{w_{j}}-a_{B j}\right|$ and $\left|\frac{w_{j}}{w_{W}}-a_{j W}\right|$ for all $j$. All of the weights should be nonnegative and the sum of the weights should be equal to 1 . Rezaei [65] formulated this problem as in the following linear problem:

$$
\min \varepsilon \text { s.t. }\left|w_{B}-a_{B j} w_{j}\right| \leq \varepsilon, \text { for all } j\left|w_{j}-a_{j W} w_{W}\right| \leq \varepsilon, \text { for all } j \sum_{j} w_{j}=1 w_{j} \geq 0, \text { for all } j
$$

The optimal value of the objective function $\left(\varepsilon^{*}\right)$ and the weights $\left(w_{1}^{*}, w_{2}^{*}, \ldots, w_{n}^{*}\right)$ are obtained by solving Problem (3). $\varepsilon^{*}$ represents the consistency of the comparisons, and values close to zero indicates a high consistency level [28]. If $\varepsilon^{*}$ is equal to zero, it means that the comparison system is fully consistent.

There are various studies that use a single decision maker or multiple decision makers for the supplier evaluation and selection problem. However, past researches have shown that decision making of a group of experts provides better results than individual decision support $[3,66]$. Therefore, three decision makers are used both in the weighting of the criteria and assessment of the suppliers. These decision makers evaluated the 17 criteria based on the steps of the BWM, and then the weights are calculated by solving a linear mathematical model with GAMS. The final weights of the criteria are determined by taking the averages of the results of the three BWM solutions.

The data on four quantitative criteria are gathered from the purchasing department. The values of the remaining thirteen qualitative criteria depend on the subjective evaluations of the three decision makers. The role, position and expertise of the decision makers are explained in the following:

(1) Decision Maker 1 is the commercial manager of the company and has a high effect on the selection of the suppliers. He has a high authority in the determination of SC stakeholders and makes regular field visits both to the foreign and local suppliers. He has a high expertise about the sector and general conditions (e.g., facility, technology level) of the suppliers.

(2) Decision Maker 2 is selected as a domain expert from the purchasing department. She has a high expertise about the procurement processes and has a closer contact with suppliers.

(3) Decision Maker 3 is a mechanical engineer and works in the purchasing department. He has a high level of technical knowledge and expertise in engineering related issues such as manufacturing processes, quality level, and technological capability of suppliers.

Decision makers have different backgrounds and expertise; hence, the evaluations of the three decision makers are also weighed by the general manager and the business development engineer by considering their roles, responsibilities and experiences. The weighted scores of the suppliers are normalized in order to scale the data on the 17 criteria within a specific range. The number of criteria is 
very high for cluster analysis; hence, a factor analysis is applied for variable reduction. Four factors are extracted from these seventeen criteria by applying Principle Component Analysis (PCA). K-means clustering algorithm $[29,42,43]$ is applied to group suppliers based on the generated four risk factors. The analysis of the data is performed by using SPSS version 20 . The results of the cluster analysis are interpreted with the risk analysis and management team in the company. The knowledge gathered by the evaluation of the clusters will be used in selecting low-risk suppliers and/or develop supplier improvement programs. This is the first study that applies cluster analysis to group suppliers based on their risk profile. In addition, this is the first time BWM and cluster analysis are used together for supplier risk assessment.

\subsection{Supplier Risk Assessment Criteria}

The identification of the supplier risk factors has a critical effect on the effectiveness of the proposed supplier evaluation and selection method. Various methods have been used to identify and define supplier risks in the literature. Some of these methods are literature review, questionnaire, rating method, and discussion $[23,64,67,68]$. In this research, first, a set of risk evaluation criteria (risk types) for suppliers is determined through reviewing the existing literature. Supplier evaluation and selection criteria vary depending on the business strategy and the need of the organization [55]. Hence, the final set of criteria is determined after several iterative and structured meetings and discussions with managers and purchasing staff in the case study company. Various issues are considered while selecting the risk criteria such as specific requirements and risk attitude of the company, and the structure of the sector.

The set of supplier evaluation criteria includes 17 different risk related criteria: $C=\left\{c_{1}, c_{2}, \ldots\right.$, $\left.c_{17}\right\}$ that are grouped under eight risk dimensions (categories). The selected risk evaluation criteria for suppliers are grouped under related risk categories and given in Figure 2. Four quantitative criteria $\left(c_{4}, c_{8}, c_{10}\right.$, and $\left.c_{11}\right)$ are typical numbers, averages and percentages. It is difficult to convert some of the risk categories into measurable variables. The values of the other 13 criteria $\left(c_{1}, c_{2}, c_{3}, c_{5}, c_{6}\right.$, $c_{7}, c_{9}$, and $\left.c_{12}-c_{17}\right)$ are determined by subjective evaluations of the three decision makers in the risk management team. These criteria are used as indicators of suppliers' risk exposure levels for different issues including poor operational performance, insufficient quality management efforts, low service level, and communication problems. In addition to operational risk types, one criteria related with catastrophic risks is also added to the study. The mixed set of risk criteria helps to incorporate different aspects of supply risks into the model, and develop a comprehensive supplier evaluation process.

Data on 72 suppliers that supply critical raw materials and parts required to produce a mill are collected, and a supplier risk data set is created. These suppliers do not produce the same products. This is a limitation of the study. Therefore, we used expert evaluations for some criteria to cope with this limitation. As an example, risks associated with technical problem solving capability of suppliers cannot be evaluated by using the number of days spent to solve unexpected problems, because it is dependent on the complexity of the product supplied by the supplier [57].

The risk criteria that are used to evaluate suppliers are explained in the following.

(1) Previous supplier assessments $\left(\mathbf{c}_{1}\right)$ : The current company makes a supplier evaluation survey to the purchasing staff for each purchasing activity. Suppliers are evaluated based on five criteria with a 1-5 scale: quality system, process control, references, technological structure, and delivery performance. The averages of the weighted ratings are calculated for each supplier. The weighted total points are used as an indicator of prior experience with the suppliers. It is an important indicator that represents the historical performance and reliability of the suppliers [35,36].

(2) Purchase (commodity) price variance $\left(\mathbf{c}_{2}\right)$ : This indicator represents the level of the supplier's price within the standard sector price. " 1 " point represents a very low price, " 5 " represents an average value, and " 9 " represents a high level of price. It represents the competitiveness of the price $[22,50]$. 


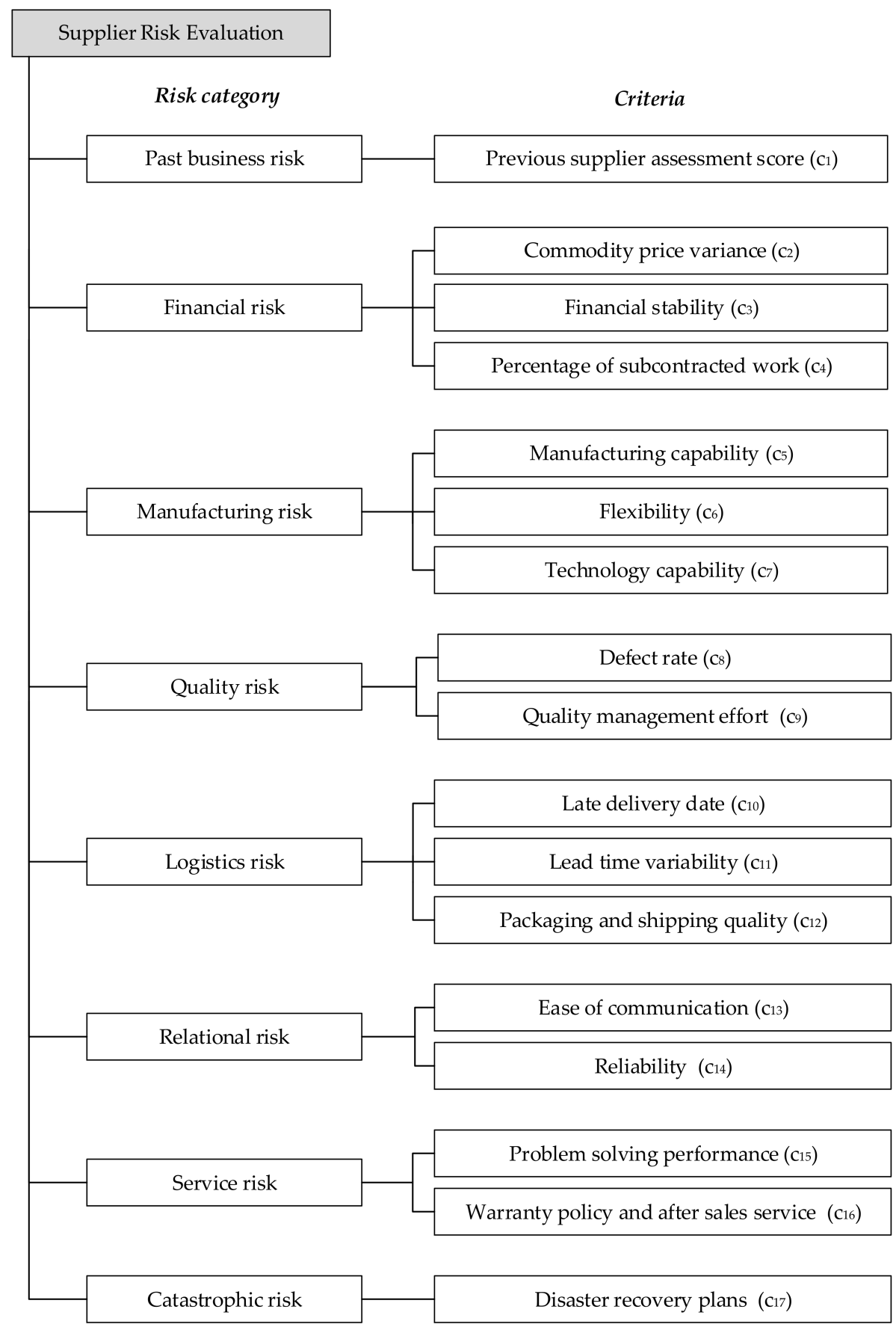

Figure 2. Main risk categories and risk types considered in the supplier assessment process.

(3) Financial condition of the supplier $\left(c_{3}\right)$ : This indicator represents the risk rating of the supplier's financial condition by considering its economic status, debt structure, market share, annual revenue and growth, and financial stability [35,55]. It is an indicator of poor financial health of the supplier [33]. Nine point indicates a high likelihood of supplier bankruptcy.

(4) Percentage of supplier's work commonly subcontracted $\left(\mathbf{c}_{4}\right)$ : It is the ratio of the supplier's work that is subcontracted $[69,70]$. Suppliers are dependent on their subcontractors for this part of their job. Hence, a high level of subcontracting leads to a high level of uncertainty and risk exposure. 
(5) Manufacturing capability $\left(c_{5}\right)$ : This indicator refers to the rating of the supplier's manufacturing capability in terms of the conditions, qualification, adequacy and capacity of the production facility, machines, equipment and employee of the supplier [34,56]. The focal company visits and evaluates its potential suppliers for an initial observation. They also make regular visits during their orders. This rating is identified by using the evaluations and observations during these field visits.

(6) Flexibility $\left(\mathbf{c}_{6}\right)$ : Supplier flexibility can be defined as the ability of the supplier to respond to changing demands and requirements of customers [33,34,36]. Suppliers are rated based on their flexibility in terms of volume, product mix, product design, and delivery date. While one point represents a high level of flexibility of the supplier, nine point indicates that the supplier is lack of flexibility.

(7) Technological capability $\left(\mathbf{c}_{7}\right)$ : It is a measure of the capability and robustness of supplier's technological systems, and used to measure technology risk [19,31]. It considers the manufacturing technology and R\&D capability of the supplier. Nine point indicates that the suppliers have a low level of technological capability, and are unable to respond to technological needs and innovations.

(8) Average defect rate of the supplier $\left(c_{8}\right)$ : Defect rate is the proportion of the number of products that do not meet quality specifications to the total number of units supplied from the supplier $[25,70]$. It is calculated by taking the average of the values in quality inspection records within the last five years. Noncompliance to quality specifications is an indicator of poor quality.

(9) Quality management effort $\left(\mathbf{c}_{9}\right)$ : It refers to the rating of the supplier based on its quality efforts (commitment to quality). The following issues are considered during assessments of suppliers; quality-related certificates, quality control activities, capability of quality management systems, quality improvement programs, and recording of quality inspections [31,37]. Nine point indicates that there is a lack of quality management efforts and programs.

(10) Late delivery rate of the supplier $\left(\mathbf{c}_{10}\right)$ : It is the ratio of the number of late deliveries to the total number of orders $[22,63]$. This indicator is calculated by using the past records.

(11) Supplier lead time variability $\left(\mathbf{c}_{11}\right)$ : This indicator is measured by dividing the difference between quoted and actual supplier lead time by the quoted lead time (in days). It is an indicator of the variation from promised delivery lead time.

(12) Packaging and shipping quality $\left(\mathbf{c}_{12}\right)$ : This indicator refers to the risk rating of the supplier's packaging and shipping functions both in terms of quality of this function and compliance to standards [50,56]. Nine point indicates that the supplier has a low level of packaging and shipping quality and it is likely to have a problem associated with the appropriateness of packaging and shipping.

(13) Ease of communication ( $\mathbf{c}_{13}$ ): This indicator refers to the overall communication rating of the supplier. It considers problems and difficulties in communicating with suppliers such as unstable and inefficient communication networks, difficulty to reach contact persons/sales representatives (e.g., unavailability or discontinuity of the responsible person), misinterpretation of the emails by suppliers, imprecise and slow communication manner, lack of transparency, unwillingness, and privacy for information sharing $[33,35,70]$. This indicator helps to identify failures in communication and coordination with suppliers.

(14) Reliability $\left(\mathbf{c}_{14}\right)$ : It represents the reliability level of the supplier based on compliance to contract terms and conditions in previous businesses, accuracy and reliability of documentation and information provided by suppliers, reputation in the sector, and references. Level of trust in the buyer-supplier relationship is a very important factor that affects the strength of business relationships and information sharing [50]. 
(15) Problem solving performance $\left(\mathbf{c}_{15}\right)$ : This indicator represents the risk level arising from ineffective and poor sales and technical support. Problem solving performance includes the response time of suppliers to a complaint, quality concern or emergency problem, problem solving capability, handling of complaints, technical support level, and remedy to correct a quality problem [22,55]. Nine point represents the irresponsiveness of the supplier.

(16) Warranty policy and after sales service $\left(\mathbf{c}_{16}\right)$ : This indicator refers to the rating of the supplier's after sales service, and warranty and claim policy (in terms of coverage of warranty and service agreements, warranty period, and satisfaction about claims) [56,71].

(17) Disaster recovery plans to deal with major disruptions $\left(\mathbf{c}_{17}\right)$ : This indicator refers to the score of a supplier based on its disaster recovery plans. Most of the suppliers are located in a close region. Hence, it is not meaningful to rank suppliers according to their risk exposure level for catastrophic risks such as earthquake, tsunami, and flood. Inadequate disruption management systems increase the risk exposure levels of companies [37]. Effective disaster recovery plans can increase the robustness of suppliers to catastrophic events.

\subsection{Weighting of the Risk Criteria by Using Best-Worst Method}

Before cluster analysis, BWM [65] is applied to identify the weights of the risk criteria that are used to evaluate suppliers. BWM is selected for several reasons [28,40];

(1) A high number of risk criteria is determined in order to increase the efficiency and broaden the scope of the analysis on the risk behavior of suppliers. Therefore, it will be difficult to weight these criteria by using traditional MCDM methods such as AHP, ANP, DEA and TOPSIS [5,14,17,31]. BWM is chosen to overcome the computational complexity of the existing methods. It is a vector-based method; hence, it requires a less number of comparisons than matrix-based MCDM methods [65].

(2) It is difficult to assign a number to express the preference between different criteria. It is the most critical factor that leads to inconsistency. BWM simplifies this pairwise comparison process and increases the consistency of the evaluations. Rezaei [28] compared BWM with AHP, and the results of the study showed that BWM gives better results in terms of consistency ratio, minimum violation, total deviation, and conformity.

Three decision makers made their evaluations on risk-related criteria individually. First, all of them chose the best (most important) and worst (least important) criteria among the 17 criteria which are explained in Section 4.2. Their choices for the best and worst criteria are given in Table 3.

Table 3. The best and worst risk criteria identified by the three decision makers.

\begin{tabular}{ccc}
\hline Decision Makers & Best Criteria & Worst Criteria \\
\hline Decision maker 1 & Commodity price variance $\left(\mathrm{c}_{2}\right)$ & Percentage of subcontracted work $\left(\mathrm{c}_{4}\right)$ \\
\hline Decision maker 2 & $\begin{array}{c}\text { Manufacturing capability }\left(\mathrm{c}_{5}\right) \text { and } \\
\text { commodity price variance }\left(\mathrm{c}_{2}\right)\end{array}$ & Percentage of subcontracted work $\left(\mathrm{c}_{4}\right)$ \\
\hline Decision maker 3 & Reliability $\left(\mathrm{c}_{14}\right)$ & Disaster recovery plans $\left(\mathrm{c}_{17}\right)$ \\
\hline
\end{tabular}

Each decision maker determined the preference of their best criterion over all the other criteria by using the nine-point scale that is given in Table 4 . Then, they determined the preference of all the criteria over their worst criterion by using the same scale.

Pairwise comparisons of the three decision makers for the best and worst criteria are given in Table 5. Due to the reciprocal property of the pairwise comparison matrix, totally $31(2 n-3)$ pairwise comparisons were conducted by each decision maker. As it can be seen from Table 5, the preference of a criterion to itself gets the value of 1 . 
Table 4. Nine-point pairwise comparison scale used in the Best-worst method (adapted from [64,72]).

\begin{tabular}{cl}
\hline Intensity of Importance & \multicolumn{1}{c}{ Verbal Meaning for Risk Criteria Comparison } \\
\hline 1 & Equally important \\
2 & Equally to moderately more important \\
3 & Moderately more important \\
4 & Moderately to strongly more important \\
5 & Strongly more important \\
6 & Strongly to very strongly more important \\
7 & Very strongly more important \\
8 & Very strongly to extremely more important \\
9 & Extremely more important \\
\hline
\end{tabular}

Table 5. Pairwise comparisons of the decision makers for the best and worst criteria.

\begin{tabular}{|c|c|c|c|c|c|c|}
\hline \multirow[b]{2}{*}{ Criteria } & \multicolumn{2}{|c|}{ Decision Maker 1} & \multicolumn{2}{|c|}{ Decision Maker 2} & \multicolumn{2}{|c|}{ Decision Maker 3} \\
\hline & $\begin{array}{c}\text { Best } \\
\text { Criterion: } c_{2}\end{array}$ & $\begin{array}{c}\text { Worst } \\
\text { Criterion: } \mathrm{c}_{4}\end{array}$ & $\begin{array}{c}\text { Best } \\
\text { Criterion: } c_{5}\end{array}$ & $\begin{array}{c}\text { Worst } \\
\text { Criterion: } \mathrm{c}_{4}\end{array}$ & $\begin{array}{c}\text { Best } \\
\text { Criterion: } c_{14}\end{array}$ & $\begin{array}{c}\text { Worst } \\
\text { Criterion: } \mathrm{c}_{17}\end{array}$ \\
\hline$c_{1}$ & 4 & 7 & 6 & 3 & 3 & 8 \\
\hline$c_{2}$ & 1 & 9 & 1 & 9 & 3 & 7 \\
\hline$c_{3}$ & 3 & 7 & 9 & 2 & 4 & 5 \\
\hline$c_{4}$ & 9 & 1 & 9 & 1 & 8 & 2 \\
\hline$c_{5}$ & 6 & 7 & 1 & 8 & 2 & 8 \\
\hline$c_{6}$ & 8 & 4 & 2 & 7 & 5 & 6 \\
\hline $\mathrm{c}_{7}$ & 6 & 7 & 2 & 6 & 1 & 9 \\
\hline$c_{8}$ & 2 & 9 & 4 & 4 & 2 & 8 \\
\hline c9 & 5 & 7 & 2 & 8 & 6 & 5 \\
\hline$c_{10}$ & 2 & 8 & 3 & 7 & 2 & 7 \\
\hline$c_{11}$ & 2 & 8 & 3 & 6 & 2 & 8 \\
\hline$c_{12}$ & 3 & 5 & 2 & 7 & 2 & 8 \\
\hline$c_{13}$ & 5 & 5 & 4 & 6 & 4 & 6 \\
\hline$c_{14}$ & 4 & 4 & 2 & 8 & 1 & 9 \\
\hline$c_{15}$ & 3 & 6 & 2 & 8 & 1 & 9 \\
\hline$c_{16}$ & 5 & 5 & 2 & 8 & 1 & 9 \\
\hline$c_{17}$ & 8 & 3 & 2 & 8 & 9 & 1 \\
\hline
\end{tabular}

The linear BWM problem (Problem (3) in Section 4.1) is solved for each decision maker separately and optimal weights are gained. The objective function value $(\varepsilon)$ that represents the consistency level of the decision makers in the three linear BWM problems are as follows: $\varepsilon_{1}=0.048, \varepsilon_{2}=0.028$, and $\varepsilon_{3}=0.027$. All of these values are close to 0 ; hence, the comparisons of the three decision makers can be accepted as consistent.

The final weights of the criteria are calculated by taking the averages of the weights that are found by the three BWM problems. Table 6 represents the average optimum values of the weights of the 17 criteria. These values are used as the weights of the criteria in the analysis part.

Table 6. Averages of the three Best-Worst method (BWM) solutions.

\begin{tabular}{cccccc}
\hline Weights of the Criteria & Values & Weights of the Criteria & Values & Weights of the Criteria & Values \\
\hline$w_{1}^{*}$ & 0.0393 & $w_{7}^{*}$ & 0.0700 & $w_{13}^{*}$ & 0.0363 \\
$w_{2}^{*}$ & 0.1063 & $w_{8}^{*}$ & 0.0673 & $w_{14}^{*}$ & 0.0757 \\
$w_{3}^{*}$ & 0.0387 & $w_{9}^{*}$ & 0.0437 & $w_{15}^{*}$ & 0.0813 \\
$w_{4}^{*}$ & 0.0130 & $w_{10}^{*}$ & 0.0710 & $w_{16}^{*}$ & 0.0723 \\
$w_{5}^{*}$ & 0.0703 & $w_{11}^{*}$ & 0.0710 & $w_{17}^{*}$ & 0.0343 \\
$w_{6}^{*}$ & 0.0403 & $w_{12}^{*}$ & 0.0677 & & \\
\hline
\end{tabular}

* Averages of the optimal weights.

\subsection{Supplier Risk Data}

This section includes the collection of data on suppliers with respect to predetermined risk factors. Suppliers are assessed based on 17 qualitative and quantitative risk related criteria. Four criteria 
include ratios, and are calculated by using past data on suppliers $\left(c_{4}, c_{8}, c_{10}\right.$ and $\left.c_{11}\right)$. The remaining thirteen criteria include qualitative data that is based on subjective evaluations of the three decision makers $\left(c_{1-3}, c_{5-7}, c_{9}, c_{12-17}\right)$. Criterion $c_{1}$ is calculated by taking the weighted average of previous subjective evaluations in the company. Suppliers are rated based on five criteria after each order with an ordinal scale from 1 to 5 (1: high performance and 5: low performance). These criteria are quality system, process control capability, references, technological structure, and delivery performance. The weights of the criteria are $0.15,0.15,0.05,0.05$, and 0.60 respectively. The weighted averages of the ratings are used as an indicator of past business risk. Data on criterion 2, commodity price variance, is gathered only from decision maker 2, because she is responsible for gathering price quotation.

Three decision makers rated suppliers based on the remaining eleven qualitative criteria by using a nine-point Likert scale that is given in Table 7. One represents extremely low and negligible risk level. Nine represents an extremely high and serious risk level.

Table 7. Nine-point Likert scale used in rating suppliers (adapted from [72]).

\begin{tabular}{cl}
\hline Risk Rating & \multicolumn{1}{c}{ Verbal Meaning } \\
\hline $\mathbf{1}$ & Extremely low and negligible risk level \\
$\mathbf{2}$ & Very low risk level \\
$\mathbf{3}$ & Low risk level \\
$\mathbf{4}$ & Slightly low risk level \\
$\mathbf{5}$ & Moderate risk level \\
$\mathbf{6}$ & Slightly high risk level \\
$\mathbf{7}$ & High risk level \\
$\mathbf{8}$ & Very high risk level \\
$\mathbf{9}$ & Extremely high and serious risk level \\
\hline
\end{tabular}

Data on suppliers are gathered by conducting three sessions with each decision maker individually. Each session is performed in a different week and suppliers are assessed based on a different set of criteria in each session. Various researchers treat ordinal values as interval data [46,73]. Similarly, the supplier risk ratings for the 13 qualitative criteria are assumed as interval in this study.

As explained in Section 4.1, each decision maker has different levels of knowledge, expertise and experience. In addition, they communicate with suppliers about different issues based on their responsibilities. Hence, first different weights are assigned for the ratings of the decision makers for each criteria. The weights are given in Table 8. These weights are assigned with the general manager and the work development specialist who is an industrial engineer. The weighted averages are calculated for the eleven criteria that are given in Table 8. Each risk factor has a different importance level for the company, hence, all values are multiplied with the weight of the current criteria (See Table 6). The preprocessing process and the cluster analysis are performed on the weighted data set.

Table 8. Weights of the evaluations of decision makers for different criteria.

\begin{tabular}{clccc}
\hline & & \multicolumn{2}{c}{ Weights of the Evaluations of Decision Makers } \\
\hline No. & \multicolumn{1}{c}{ Criteria } & Decision Maker 1 & Decision Maker 2 & Decision Maker 3 \\
\hline $\mathbf{1}$ & Financial condition of the supplier $\left(\mathrm{c}_{3}\right)$ & 0.6 & 0.3 & 0.1 \\
$\mathbf{2}$ & Manufacturing capability $\left(\mathrm{c}_{5}\right)$ & 0.3 & 0.2 & 0.5 \\
$\mathbf{3}$ & Flexibility $\left(\mathrm{c}_{6}\right)$ & 0.2 & 0.4 & 0.4 \\
$\mathbf{4}$ & Technological capability $\left(\mathrm{c}_{7}\right)$ & 0.3 & 0.2 & 0.5 \\
$\mathbf{5}$ & Quality management effort $(\mathrm{c} 9)$ & 0.2 & 0.4 & 0.4 \\
$\mathbf{6}$ & Packaging and shipping quality $\left(\mathrm{c}_{12}\right)$ & 0.2 & 0.4 & 0.4 \\
$\mathbf{7}$ & Ease of communication $\left(\mathrm{c}_{13}\right)$ & 0.2 & 0.5 & 0.3 \\
$\mathbf{8}$ & Reliability $\left(\mathrm{c}_{14}\right)$ & 0.2 & 0.4 & 0.4 \\
$\mathbf{9}$ & Problem solving performance $\left(\mathrm{c}_{15}\right)$ & 0.2 & 0.4 & 0.4 \\
$\mathbf{1 0}$ & Warranty policy and after sales service $\left(\mathrm{c}_{16}\right)$ & 0.2 & 0.4 & 0.2 \\
$\mathbf{1 1}$ & Disaster recovery plans $\left(\mathrm{c}_{17}\right)$ & 0.6 & 0.2 & 0.4 \\
\hline
\end{tabular}


Some of the variables are measured on different scales. Most of the clustering methods are sensitive to the scales and standard deviation of different variables [74]; hence, a standardization process is needed before measuring their similarity. The 17 risk variables are converted to $\mathrm{z}$ scores and the standardized values are used in the latter analysis. Cronbach's alpha is calculated in order to measure the internal consistency and reliability of the data set. It is considered to be a measure of scale reliability [75]. Cronbach's alpha for the 17 criteria is 0.845 . This value is greater than 0.70 meaning that the suppliers have a relatively high internal consistency.

There are 17 supplier evaluation criteria, but clustering algorithms generally perform well with a less number of variables. Besides, there is an inter-relationship between different risk factors [10,59]. Therefore, a factor analysis is performed to examine the relationship between these criteria and group some of them. Factor analysis is a statistical technique that is used to analyze the structure of interrelationships (correlations) among variables and reduce a large number of variables into a less number of factors $[74,75]$.

A correlation matrix is constructed based on supplier risk data and given in Figure 3. Correlation coefficient is a measure of the strength of the linear relationship between two variables [76]. The following issues are regarded to check the appropriateness of factor analysis [73]: (i) The data set includes more than 50 observations. (ii) There is a high correlation between some of the risk types. The correlation coefficient ranges from -1 to +1 , and the closer the value is to +1 , the higher is the positive linear relationship between the variables [73]. Correlations between some of the risk factors are as follows: late delivery date and lead time variability: 0.961, problem solving performance and warranty policy \& after sales service: 0.845 , and flexibility and manufacturing capability: 0.719 . The significant correlations are also determined by applying a two-tailed hypothesis testing both at the 0.05 and 0.01 levels and also marked in Figure 3. (iii) The ratio of the number of observations (sample size, 72) to the number of variables (17) is approximately four. Generally, at least four or five times is acceptable according to most of the researchers.

\begin{tabular}{|c|c|c|c|c|c|c|c|c|c|c|c|c|c|c|c|c|c|}
\hline \multicolumn{18}{|c|}{ Pearson Correlations } \\
\hline & $c_{1}$ & & & $c_{4}$ & $c_{5}$ & $c_{6}$ & $c_{7}$ & $\mathrm{c}_{8}$ & $c_{9}$ & $c_{10}$ & $c_{11}$ & & $\mathbf{c}_{13}$ & $c_{14}$ & $c_{15}$ & $c_{16}$ & $c_{17}$ \\
\hline$c_{1}$ & 1 & -0.058 & 57 & & 0.029 & & 0.094 & $0.283^{\circ}$ & 0.156 & 0.127 & 0.128 & 0.085 & 0.103 & 0.218 & 0.211 & $0.240^{\circ}$ & $0.276^{*}$ \\
\hline$c_{2}$ & .058 & & 27 & & & & & & & & & & & & & & \\
\hline$c_{3}$ & 157 & 127 & & 6 & & & & .010 & & & 009 & 383" & 104 & $0.324^{-\prime}$ & 0.203 & $296^{*}$ & \\
\hline$c_{4}$ & 152 & $98^{\circ}$ & 6 & & 110 & -0.08 & 04 & 0.202 & & 7 & 095 & 5 & 086 & & 0.046 & 001 & 27 \\
\hline$c_{5}$ & 029 & 097 & 5 & & & 719"- & 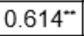 & $3^{*}$ & & 0.08 & 9 & $3 s$ & 8 & $2^{*}$ & 34 & $1^{-*}$ & \\
\hline$c_{6}$ & 131 & 020 & $38^{-1}$ & 081 & $19^{*-}$ & & $0.599^{-\prime}$ & 0.141 & $332^{*}$ & 0.044 & 0.023 & $408^{*}$ & $0.235^{\circ}$ & $0.456^{-\prime}$ & $0.449^{-*}$ & $0.473^{*}$ & \\
\hline$c_{7}$ & 094 & 057 & $473^{*}$ & .004 & $314^{*}$ & $0.599^{-}$ & & .064 & $408^{-\prime}-1-x-10$ & 0.197 & -0.151 & 0.160 & $.350^{-*}$ & $283^{\circ}$ & $0.234^{\circ}$ & 229 & $259^{\circ}$ \\
\hline$c_{8}$ & 283 & 103 & 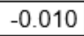 & 2 & & & 0 & & 190 & $821^{-4}$ & $0.828^{*-}$ & & 0 & & $325^{*-}$ & $0.337^{*}$ & 2 \\
\hline$c_{9}$ & 156 & 130 & $523^{*}$ & 0.195 & $5588^{-1}$ & $0.632^{*}$ & $0.408^{*-}$ & & & 0.11 & 0.075 & $0.441^{*}$ & $0.286^{*}$ & $0.684^{--}$ & $482^{-*}$ & $0.629^{*}$ & $6^{*-}$ \\
\hline$c_{10}$ & 127 & 027 & 056 & 12 & 8 & 0. & 197 & $1^{-*}$ & & & $0.961^{*}$ & 0.194 & -0.019 & 79 & $346^{*-}$ & $0.361^{*}$ & 7"* \\
\hline$c_{11}$ & 128 & 033 & 009 & 95 & & 0.02 & -0.151 & 828"- & & 1* & & 0.186 & -0.0 & 22 & $4^{*-}$ & $0.327^{-*}$ & $37^{* \prime}$ \\
\hline$c_{12}$ & 085 & 0.067 & $0.383^{*}$ & -0.015 & $395^{-*}$ & $0.408^{*}$ & 0.16 & 0.206 & $441^{-*}$ & & 186 & & $0.375^{*}$ & $0.320^{-\prime}$ & $0.361^{*}$ & $0.361^{*}$ & $1^{*}$ \\
\hline$c_{13}$ & 103 & 142 & 4 & 0.086 & 198 & 0.23 & $0.350^{*-}$ & 0.000 & & -0.019 & -0.034 & $375^{*}$ & & 0.211 & $420^{-1}$ & $0.453^{*}$ & $13^{*}$ \\
\hline$c_{14}$ & 218 & 141 & $324^{*-}$ & -0.116 & $442^{*}$ & $0.456^{*}$ & $0.283^{\circ}$ & 0.208 & $684^{-1}$ & 0.17 & 0.122 & $320^{-*}$ & 211 & & $0.491^{*}$ & $0.583^{*}$ & $602^{\prime \prime}$ \\
\hline$c_{15}$ & 211 & 0.088 & 203 & 0.046 & $347^{*}$ & $0.449^{*}$ & $0.234^{\circ}$ & $0.325^{*}$ & $0.482^{-*}$ & $0.346^{*}$ & $0.344^{*}$ & $0.361^{*}$ & $0.420^{-*}$ & $0.491^{-}$ & & $0.845^{*}$ & $0.790^{* \prime}$ \\
\hline$c_{16}$ & $40^{\circ}$ & 165 & $296^{\circ}$ & 0.001 & & 0.47 & & $337^{-1}$ & & 0.36 & $0.327^{*}$ & $0.361^{*}$ & $0.453^{-}$ & & 5 & & $0.804^{*}$ \\
\hline & $276^{\circ}$ & 0.216 & $378^{*-}$ & 0.027 & $404^{*-}$ & $0.403^{*}$ & $0.259^{\circ}$ & $0.372^{*}$ & $0.566^{*}$ & $0.417^{-}$ & $0.437^{*}$ & $0.311^{*}$ & $0.343^{-\prime}$ & $0.602^{-*}$ & $0.790^{-*}$ & $0.804^{*}$ & \\
\hline
\end{tabular}

${ }^{*}$ Correlation is significant at the 0.05 level (2-tailed); ${ }^{* *}$ Correlation is significant at the 0.01 level (2-tailed).

Figure 3. Correlation matrix of 17 risk criteria.

Bartlett's test of sphericity and Kaiser-Meyer-Olkin (KMO) tests are also used to test the appropriateness of factor analysis [76]. The test statistic for the Bartlett's test is 835.258 and the significance level is very low; hence, the null hypothesis is rejected. The KMO statistic measures the sampling adequacy, and its value is 0.761 for the supplier risk data set $(>0.5)$. This indicates that the correlations between pairs of risk variables can be explained by other variables. After checking the 
assumptions of the factor analysis and the results of the formal statistical tests, it is seen that factor analysis can be performed in the supplier risk data set efficiently.

Principle component analysis (PCA) approach [73-75] is selected for factor analysis and applied in SPSS 20. This dimension reduction technique helps to represent a set of variables in terms of a lower number of uncorrelated variables by using algebraic and geometric principles to create linear combinations of these variables [76]. The first factor accounts for the maximum amount of total variance in the data set. Then, the variance explained by the first factor is removed and the maximum variance is extracted for each succeeding component similarly by extracting as much variability as possible. The number of factors are determined based on Kaiser Criterion that proposes to extract factors with an eigenvalue greater than 1 . The scree plot in Figure 4 represents the eigenvalues plotted against the number of factors. As it is seen from the figure, a break occurs in four factors. Based on the eigenvalue criteria and the scree plot, four factors seem reasonable for supplier risk data. The extracted four factors account for approximately $34 \%, 17 \%, 9.9 \%$ and $7 \%$ of total variance respectively. These four factors totally account for $68.225 \%$ of the total variance $(>65 \%)$.

17 risk types are reduced to 4 factors. The risk types that have a correlational relationship are reduced to one variable/factor. However, the component matrix represents that the four factors are correlated with many risk types, and the interpretation of such a complex matrix is not very reasonable. Therefore, Varimax procedure, which is the most common rotation method, is performed to transform the component matrix to a simpler matrix. The aim of the Varimax procedure is to minimize the number of variables with high loadings on a factor and increase the interpretability of the factor matrix [73].

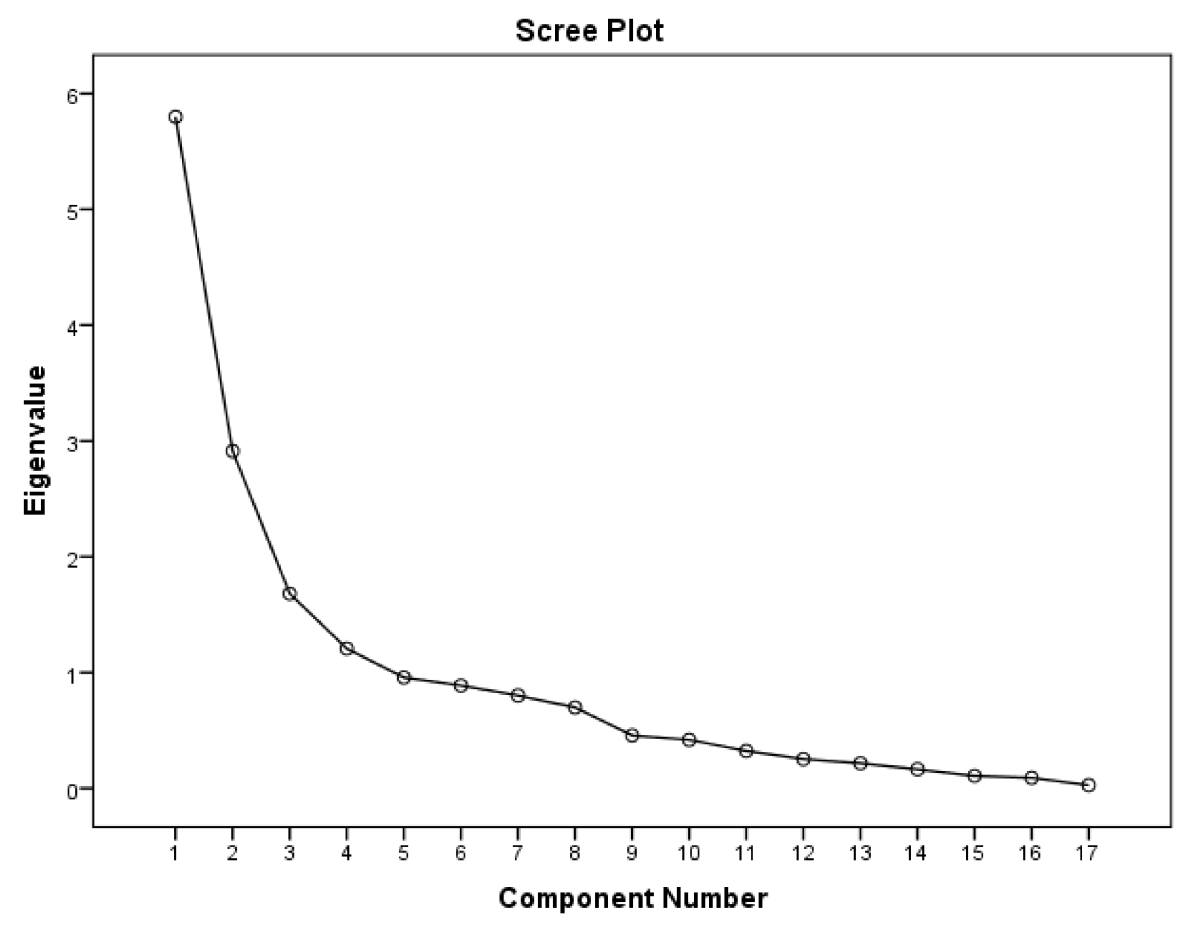

Figure 4. Scree plot of eigenvalues.

Based on the correlations in the rotated component matrix, 17 risk variables are grouped under the four factors that are given in Table 9. General labels are assigned to the extracted factors by considering the risk variables that are covered by each factor. Factor 1 contains risk types related with the general structure, and manufacturing, technological and logistics capabilities of the suppliers. Factor 2 includes risks related with the previous assessments, reliability, communication, after sales service, and problem solving capability of the suppliers. Factor 3 covers the risks related with quality 
and delivery performance of the suppliers (operational performance). Factor 4 covers only two risk types; commodity price variance and percentage of subcontracted work. Companies that use subcontractors also bear the profits of these companies. This grouping of the variables is reasonable.

Table 9. Risk factors and variables.

\begin{tabular}{ll}
\hline $\begin{array}{l}\text { Factor 1: Risks related with the general condition and } \\
\text { capabilities of the supplier }\end{array}$ & $\begin{array}{l}\text { Factor 2: Risks related with the supplier's reliability and } \\
\text { commitment to business }\end{array}$ \\
\hline - Financial condition of the supplier $\left(\mathrm{c}_{3}\right)$ & - Previous supplier assessment score $\left(\mathrm{c}_{1}\right)$ \\
- Manufacturing capability $\left(\mathrm{c}_{5}\right)$ & - Ease of communication $\left(\mathrm{c}_{13}\right)$ \\
- Flexibility $\left(\mathrm{c}_{6}\right)$ & - Reliability $\left(\mathrm{c}_{14}\right)$ \\
- Technological capability $\left(\mathrm{c}_{7}\right)$ & - Problem solving performance $\left(\mathrm{c}_{15}\right)$ \\
- Quality management effort $\left(\mathrm{c}_{9}\right)$ & - Warranty policy and after sales service $\left(\mathrm{c}_{16}\right)$ \\
- Packaging and shipping quality $\left(\mathrm{c}_{12}\right)$ & - Disaster recovery plans $\left(\mathrm{c}_{17}\right)$ \\
\hline Factor 3: Operational risks & Factor 4: Price risk \\
\hline - Defect rate $\left(\mathrm{c}_{8}\right)$ & - Commodity price variance $\left(\mathrm{c}_{2}\right)$ \\
- Late delivery date $\left(\mathrm{c}_{10}\right)$ & - Percentage of subcontracted work $\left(\mathrm{c}_{4}\right)$ \\
- Lead time variability $\left(\mathrm{c}_{11}\right)$ & \\
\hline
\end{tabular}

\subsection{Cluster Analysis}

The aim of the case study is to cluster the core suppliers of the case study company based on different risk characteristics. Totally, 72 existing suppliers are evaluated by using preprocessed risk data and 4 risk factors. Clustering algorithm aims to find the similarities among suppliers based on different risk indicators. There is a myriad of clustering algorithms in the literature [41]. In this study, k-means clustering algorithm $[43,74]$, which is one of the most popular clustering algorithms, is applied to group suppliers based on their risk attributes by using SPSS version 20. K-means clustering algorithm groups observations into $\mathrm{k}$ clusters where $\mathrm{k}$ is an input parameter. It iteratively assigns observations into clusters based on their distance to the mean of the clusters. The means of the clusters are computed in each iteration. K-means algorithm is selected for several reasons such as efficiency, practicability, high computational speed, and ease of interpretation [29,42].

Three clusters with different risk exposure levels are generated by using k-means clustering algorithm. These clusters include 19, 11 and 42 suppliers, respectively. Final cluster centers are represented with a bar chart in Figure 5. The spider web diagram in Figure 6 also compares the final cluster centers for the four factors. If we compare the final cluster centers for factor 1 and 2, we see that cluster 3 has the highest risk level and cluster 2 has the lowest risk level in terms of the risks related with their general capabilities and commitment to business. Clusters 1 and 3 have the same order based on factor 3, but the risk level of cluster 2 changes from the lowest to the biggest for this factor. It means that the suppliers in cluster 2 have a low risk level related with their managerial, manufacturing, problem solving capability, and relational performance. However, these companies have a low operational performance in terms of quality and delivery performance. Based on factor 4 , commodity price variance and percentage of subcontracted work, the highest risk profile belongs to cluster 3 and the lowest risk level is observed in cluster 1. Cluster 3 has a higher risk level for the three factors. Based on the evaluation of the clusters for the four factors, we can conclude that the suppliers in cluster 3 has the highest risk profile. We need to consider the supplier evaluations for the 17 risk factors and the weights of the risk criteria to reach a conclusion for supplier clusters 1 and 2. 


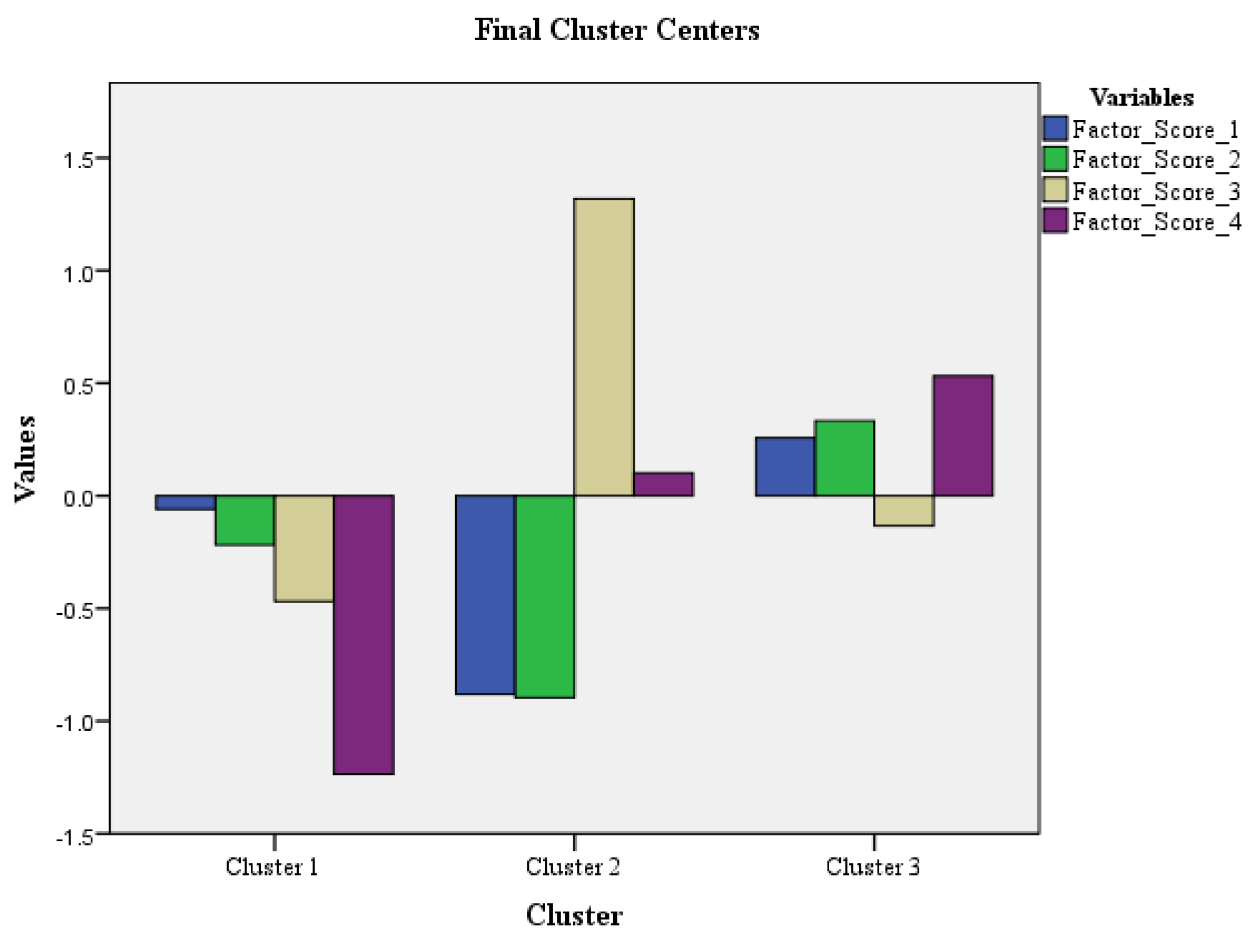

Figure 5. Bar chart of final cluster centers.

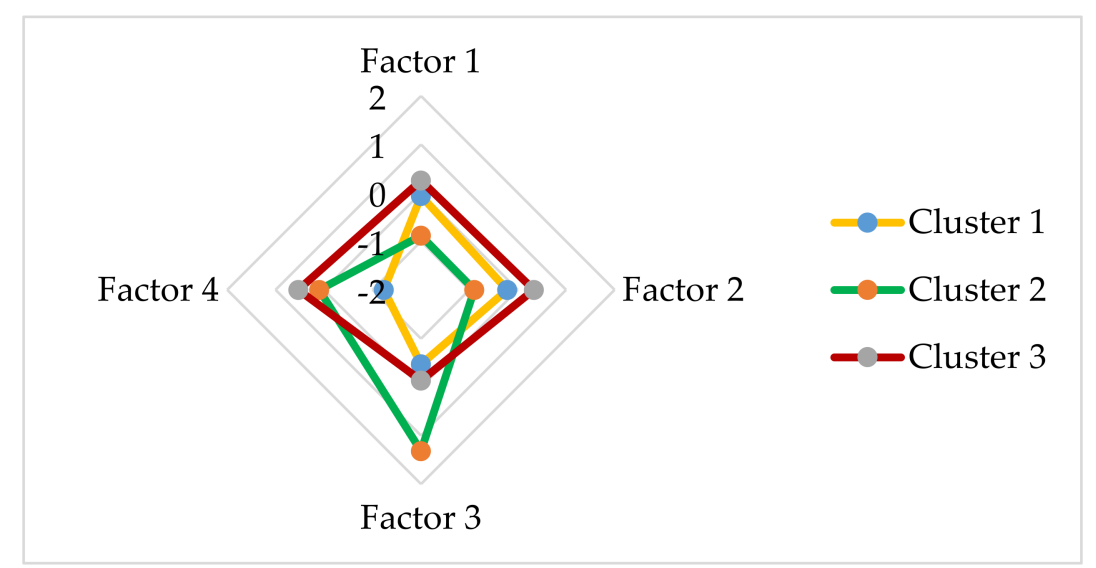

Figure 6. Spider web diagram of the cluster centers for the four factors.

An ANOVA test is applied to examine whether there are significant differences between risk factors in different clusters. The ANOVA table for the cluster analysis is given in Table 10. As it is seen from the table, the four factors have a significant effect on clusters.

Table 10. ANOVA table for k-means clustering analysis.

\begin{tabular}{lcccccc}
\hline & \multicolumn{2}{c}{ Cluster } & \multicolumn{2}{c}{ Error } & \multirow{2}{*}{ F } & Sig. \\
\cline { 2 - 5 } & Mean Square & df & Mean Square & df & & \\
\hline Factor_score_1 & 5.689 & 2 & 0.864 & 69 & 6.584 & 0.002 \\
Factor_score_2 & 7.200 & 2 & 0.820 & 69 & 8.778 & 0.000 \\
Factor_score_3 & 12.016 & 2 & 0.681 & 69 & 17.652 & 0.000 \\
Factor_score_4 & 20.511 & 2 & 0.434 & 69 & 47.212 & 0.000 \\
\hline
\end{tabular}




\subsection{Results and Discussion}

The raw data was examined in order to understand the risk structure of each supplier cluster and provide a more accurate interpretation of the results. Figure 7 represents the mean of the 17 risk criteria for the three clusters. Dark grey cells show the highest mean values for the risk types. Medium grey cells represent medium scores, and light grey cells represent the lowest risk scores. Cluster 3 had the highest risk scores for most of the risk types. This supplier cluster can be labeled as "suppliers with a high risk level". These results are compatible with the spider web diagram of the cluster centers for the four factors (See Figure 6). Cluster 2 had the lowest scores for most of the risk types related with the capabilities and commitment to business (e.g., flexibility, technological capability, packaging and shipping quality, problem solving performance, warranty policy and after sales service). Cluster 2 can be labeled as "suppliers with a low risk level". However, the suppliers in this cluster had the highest level of defect rate and delivery lateness. The commodity price variance and percentage of subcontracted work criteria had high values for these suppliers too. The high defect rate and delivery delays can be explained by the dependency on subcontractors for some degree. In addition, although suppliers in cluster 2 had a high level of commitment to quality management efforts, the quality problems resulting from their subcontractors affected their performance. The suppliers in cluster 1 had average risk scores for most of the risk types. Cluster 1 can be labeled as "suppliers with a medium risk level". However, they had the lowest risk levels for the following five risks: commodity price variance, percentage of subcontracted work, defect rate, late delivery date, and lead time variability.

\begin{tabular}{|l|c|c|c|}
\hline & Cluster 1 & Cluster 2 & Cluster 3 \\
\hline Previous supplier assessment score (c1) & 2.39 & 2.09 & 2.29 \\
\hline Commodity price variance (c2) & 4.63 & 6.82 & 7.31 \\
\hline Financial condition of the supplier (c3) & 4.54 & 3.91 & 4.91 \\
\hline Percentage of subcontracted work (c4) & 0.13 & 0.34 & 0.54 \\
\hline Manufacturing capability (cs) & 4.93 & 4.16 & 5.13 \\
\hline Flexibility (c6) & 4.84 & 4.27 & 5.07 \\
\hline Technological capability (c) & 4.85 & 4.12 & 5.20 \\
\hline Defect rate (cs) & 0.12 & 0.26 & 0.13 \\
\hline Quality management effort (c9) & 4.93 & 3.51 & 4.83 \\
\hline Late delivery date (c10) & 0.11 & 0.32 & 0.15 \\
\hline Lead time variability (c11) & 0.10 & 0.35 & 0.17 \\
\hline Packaging and shipping quality (c12) & 5.38 & 4.91 & 5.92 \\
\hline Ease of communication (c15) & 3.95 & 3.21 & 4.62 \\
\hline Reliability (c14) & 4.79 & 3.64 & 4.80 \\
\hline Problem solving performance (c15) & 4.54 & 4.33 & 5.43 \\
\hline Warranty policy and after sales service (c16) & 4.52 & 4.35 & 5.45 \\
\hline Disaster recovery plans (c17) & 4.44 & 4.36 & 5.35 \\
\hline
\end{tabular}

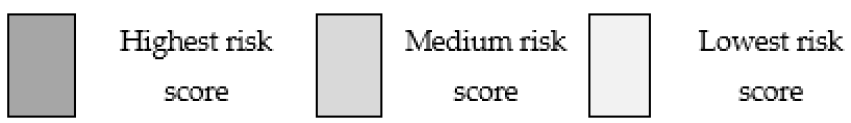

Figure 7. Means of the 17 risk types for the three supplier clusters. 
The results of the analysis are interpreted with the domain experts in the case study company. They stated that most of the suppliers in Cluster 1 and Cluster 3 sold simple products that provided the opportunity to hold stock. In addition, most of the suppliers in Cluster 2 produced complex products. These issues explained the different cluster profiles for defect rate, late delivery date, and lead time variability. A product complexity variable may be added to the analysis.

Cluster profiles differed for the previous supplier assessment scores too. The company implements supplier development plans if a supplier had bad scores for a performance factor. Therefore, previous supplier assessment scores may be collected before an improvement has been applied.

The results of the cluster analysis were compatible with the experience of the company. The interpretation of the results provides insights for supplier risk management actions. Garcia et al. [32] examined the purchasing process under three different steps. The supplier evaluation part covers a priori evaluation step that covers both current and new suppliers, and the ranking of homologated suppliers. The supplier selection part includes the choice of the ranked suppliers. The proposed clustering based supplier risk assessment approach can be used in all of the steps of the purchasing process. However, this decision affects the interpretation of the results of the cluster analysis and the identification of the actions that will be taken based on these results. The company may prefer to work with the suppliers in Cluster 2, or they may consider the weights of the risk criteria that are identified in Section 4.3. The selection of the most desirable supplier cluster may depend on these weights. As an example, commodity price variance was determined as the most important risk criterion for the case study company. The company may choose one of these clusters by considering the importance of this criterion. As a third approach, the company may create supplier development programs to improve the risky areas in the supplier clusters. The company may provide feedback information to unsatisfactory suppliers about their risk profile and the risky areas that need improvement.

\section{Conclusions}

Companies may face significant supply risk problems by overlooking supplier related threats in their supplier evaluation and selection process. The case study company produces highly customized and configured products, and uses a make to order production strategy to become more flexible and responsive to the product variability. Supplier evaluation and selection is one of the most critical and strategic processes in the company. Therefore, supplier related risks should be decreased at the beginning of the procurement function by eliminating unreliable and risky suppliers. This can be achieved by considering risk levels of the suppliers for different risk types. While there are various studies in the supplier evaluation and selection literature, a limited number of studies consider suppliers' risk levels with a multi-dimensional approach. In addition, there are very few studies on the use of clustering to generate supplier groups by considering suppliers' different attributes or business behaviors. Therefore, this study aims to contribute to these two research gaps by proposing a clustering-based model for supplier evaluation and selection problem, considering different dimensions of supply risk. Clustering approach provides to obtain different groups of alternative suppliers with similar supply risk levels. These supplier clusters also give the opportunity to produce specific supplier development programs and risk mitigation efforts for different clusters based on their characteristics.

The proposed approach is applied in a company in the heavy machinery sector. The main and most highly selling product of the company is mill. Therefore, the suppliers of the core parts of a mill are selected for the cluster analysis. Seventy-two core suppliers of the company are evaluated based on seventeen qualitative and quantitative risk criteria that are categorized under eight different risk dimensions. Four quantitative and 13 qualitative criteria are identified through literature review, and several iterative and structured meetings and discussions with managers and purchasing staff in the case study company. Besides quantitative supplier evaluation criteria, both tangible and qualitative criteria are also used in order to cover various dimensions of SC risks (e.g., reliability, 
ease of communication, disaster recovery plans). Risk evaluation criteria are assessed by three decision makers by using the BWM which is a new MCDM method [65]. Then, four factors are extracted from seventeen risk criteria by applying PCA. K-means clustering algorithm is applied to group suppliers based on the generated risk factors, and three different supplier clusters are created with different risk levels.

Based on the evaluation of the clusters for the four risk factors, we can conclude that the suppliers in cluster 3 have the highest risk profile. We need to consider the supplier evaluations for the 17 risk factors and the weights of the risk criteria to reach a conclusion for supplier clusters 1 and 2 . The raw data are examined in order to understand the risk structure of each supplier cluster and reach a more accurate interpretation of the results. The mean of the 17 risk criteria for the three clusters are calculated and evaluated. Cluster 3 has the highest risk scores for most of the risk types and can be labeled as "suppliers with a high risk level". Cluster 2 has the lowest scores for most of the risk types related with the capabilities and commitment to business; therefore, it can be labeled as "suppliers with a low risk level". The suppliers in cluster 1 have average risk scores; hence, Cluster 1 can be labeled as "suppliers with a medium risk level". The company may prefer to work with the suppliers in Cluster 2, or they may consider the weights of the risk criteria to make a final decision.

This study is novel in terms of two dimensions: (i) application of cluster analysis to group suppliers based on their risk profile, and (ii) application of BWM and cluster analysis in the same model for supplier evaluation. Supply risks may be decreased with the consideration of supplier related risk factors in the supplier evaluation and selection phase. Suppliers with a high-risk profile can be eliminated or supplier improvement programs can be developed based on the results of the analysis. The interpretation of the results also provides insights for supplier risk management actions to mitigate supply risk.

For future research, different clustering algorithms can be applied on the supplier risk data. These alternative techniques can be compared based on the number of clusters, performance and accuracy. In addition, fuzzy logic may also be incorporated into the model in order to take into account the uncertainty in the preferences of the decision makers.

Acknowledgments: This study is a part of Merve Er Kara's PhD thesis that is supported by Marmara University Scientific Research Project Coordination Unit (BAPKO) with FEN-C-DRP-100914-0339 project number.

Author Contributions: Both of the researchers gave the same contribution.

Conflicts of Interest: The authors declare no conflict of interest.

\section{References}

1. Hamdi, F.; Ghorbel, A.; Masmoudi, F.; Dupont, L. Optimization of a supply portfolio in the context of supply chain risk management: Literature review. J. Intell. Manuf. 2018, 29, 763-788. [CrossRef]

2. Nair, A.; Jayaram, J.; Das, A. Strategic purchasing participation, supplier selection, supplier evaluation and purchasing performance. Int. J. Prod. Res. 2015, 53, 6263-6278. [CrossRef]

3. Wetzstein, A.; Hartmann, E.; Benton, W.C.; Hohenstein, N.O. A systematic assessment of supplier selection literature-State-of-the-art and future scope. Int. J. Prod. Econ. 2016, 182, 304-323. [CrossRef]

4. $\quad$ Er Kara, M.; Yurtsever, Ö.; Oktay Firat, S.Ü. Sustainable Supplier Evaluation and Selection Criteria. In Social and Economic Perspectives on Sustainability; Erdoğdu, M.M., Mermod, A.Y., Aşkun Yıldırım, O.B., Eds.; IJOPEC Publication: London, UK, 2016; pp. 159-168, ISBN 978-0-9932118-1-2.

5. Guo, Z.; Liu, H.; Zhang, D.; Yang, J. Green Supplier Evaluation and Selection in Apparel Manufacturing Using a Fuzzy Multi-Criteria Decision-Making Approach. Sustainability 2017, 9, 650. [CrossRef]

6. Fang, C.; Liao, X.; Xie, M. A hybrid risks-informed approach for the selection of supplier portfolio. Int. J. Prod. Res. 2016, 54, 2019-2034. [CrossRef]

7. Hamdi, F.; Dupont, L.; Ghorbel, A.; Masmoudi, F. Supplier selection and order allocation under disruption risk. IFAC-Pap. Online 2016, 49, 449-454. [CrossRef]

8. Patra, K.; Mondal, S.K. Multi-item Supplier Selection Model with Fuzzy Risk Analysis Studied by Possibility and Necessity Constraints. Fuzzy Inf. Eng. 2015, 7, 451-474. [CrossRef] 
9. Vahidi, F.; Torabi, S.A.; Ramezankhani, M.J. Sustainable supplier selection and order allocation under operational and disruption risks. J. Clean. Prod. 2018, 174, 1351-1365. [CrossRef]

10. Er Kara, M.; Oktay Fırat, S.Ü. Supply Chain Risks: Literature Review and a New Categorization. Beykent Univ. J. Sci. Eng. 2017, 10, 31-60.

11. Lintukangas, K.; Kähkönen, A.K.; Ritala, P. Supply risks as drivers of green supply management adoption. J. Clean. Prod. 2016, 112, 1901-1909. [CrossRef]

12. Waters, D. Identifying risks. In Supply Chain Risk Management: Vulnerability and Resilience in Logistics, 2nd ed.; Kogan Page: London, UK, 2011; pp. 99-128, ISBN 978-0-7494-6393-9.

13. Manners-Bell, J. Supply Chain Risk Management: Understanding Emerging Threats to Global Supply Chains, 2nd ed.; Kogan Page: London, UK, 2018; ISBN 978-0-7494-8015-8.

14. Chen, P.S.; Wu, M.T. A modified failure mode and effects analysis method for supplier selection problems in the supply chain risk environment: A case study. Comput. Ind. Eng. 2013, 66, 634-642. [CrossRef]

15. PrasannaVenkatesan, S.; Goh, M. Multi-objective supplier selection and order allocation under disruption risk. Transp. Res. 2016, 95, 124-142. [CrossRef]

16. Zhang, X.; Huang, J.Z.; Qian, D.; Xu, J.; Jing, L. Supplier Categorization with K-Means Type Subspace Clustering. In Frontiers of WWW Research and Development-APWeb 2006; Zhou, X., Li, J., Shen, H.T., Kitsuregawa, M., Zhang, Y., Eds.; Lecture Notes in Computer Science; Springer: Berlin, Germany, 2006; Volume 3841, pp. 226-237. [CrossRef]

17. Ha, S.H.; Krishnan, R. A hybrid approach to supplier selection for the maintenance of a competitive supply chain. Expert Syst. Appl. 2008, 34, 1303-1311. [CrossRef]

18. Haghighi, P.S.; Moradi, M.; Salahi, M. Supplier Segmentation using Fuzzy Linguistic Preference Relations and Fuzzy Clustering. Int. J. Intell. Syst. Appl. 2014, 5, 76-82. [CrossRef]

19. Heidarzade, A.; Mahdavi, I.; Mahdavi-Amiri, N. Supplier selection using a clustering method based on a new distance for interval type-2 fuzzy sets: A case study. Appl. Soft Comput. 2016, 38, 213-231. [CrossRef]

20. Che, Z.H.; Wang, H.S. A hybrid approach for supplier cluster analysis. Comput. Math. Appl. 2010, 59, 745-763. [CrossRef]

21. Khaleie, S.; Fasanghari, M.; Tavassoli, E. Supplier selection using a novel intuitionist fuzzy clustering approach. Appl. Soft Comput. 2012, 12, 1741-1754. [CrossRef]

22. Chan, H.K.; Wang, X. An Integrated Fuzzy Approach for Aggregative Supplier Risk Assessment. In Fuzzy Hierarchical Model for Risk Assessment: Principles, Concepts, and Practical Applications; Springer: London, UK, 2013; pp. 45-69. [CrossRef]

23. Torres-Ruiz, A.; Ravindran, A.R. Multiple criteria framework for the sustainability risk assessment of a supplier portfolio. J. Clean. Prod. 2018, 172, 4478-4493. [CrossRef]

24. Dong, Q.; Cooper, O. An orders-of-magnitude AHP supply chain risk assessment framework. Int. J. Prod. Econ. 2016, 182, 144-156. [CrossRef]

25. Nekooie, M.A.; Sheikhalishahi, M.; Hosnavi, R. Supplier selection considering strategic and operational risks: A combined qualitative and quantitative approach. Prod. Eng. Res. Dev. 2015, 9, 665-673. [CrossRef]

26. Wu, D.D.; Zhang, Y.; Wu, D.; Olson, D.L. Fuzzy multi-objective programming for supplier selection and risk modeling: A possibility approach. Eur. J. Oper. Res. 2010, 200, 774-787. [CrossRef]

27. Mavi, R.K.; Goh, M.; Mavi, N.K. Supplier selection with Shannon entropy and fuzzy TOPSIS in the context of supply chain risk management. Procedia Soc. Behav. Sci. 2016, 235, 216-225. [CrossRef]

28. Rezaei, J. Best-worst multi-criteria decision-making method. Omega 2015, 53, 49-57. [CrossRef]

29. Witten, I.H.; Frank, E.; Hall, M.A.; Pal, C.J. Data Mining: Practical Machine Learning Tools and Techniques, 4th ed.; Morgan Kaufmann: Burlington, MA, USA, 2017; ISBN 978-0-12-804291-5.

30. Kuo, T.C.; Hsu, C.W.; Li, J.Y. Developing a Green Supplier Selection Model by Using the DANP with VIKOR. Sustainability 2015, 7, 1661-1689. [CrossRef]

31. Govindan, K.; Rajendran, S.; Sarkis, J.; Murugesan, P. Multi criteria decision making approaches for green supplier evaluation and selection: A literature review. J. Clean. Prod. 2015, 98, 66-83. [CrossRef]

32. Garcia, N.; Puente, J.; Fernandez, I.; Priore, P. Suitability of a Consensual Fuzzy Inference System to Evaluate Suppliers of Strategic Products. Symmetry 2018, 10, 22. [CrossRef]

33. Kull, T.J.; Talluri, S. A Supply Risk Reduction Model Using Integrated Multicriteria Decision Making. IEEE Trans. Eng. Manag. 2008, 55, 409-419. [CrossRef] 
34. Luthra, S.; Govindan, K.; Kannan, D.; Mangla, S.K.; Garg, C.P. An integrated framework for sustainable supplier selection and evaluation in supply chains. J. Clean. Prod. 2017, 140, 1686-1698. [CrossRef]

35. Chen, Y.J. Structured methodology for supplier selection and evaluation in a supply chain. Inf. Sci. 2011, 181, 1651-1670. [CrossRef]

36. Lee, A.H.I. A fuzzy supplier selection model with the consideration of benefits, opportunities, costs and risks. Expert Syst. Appl. 2009, 36, 2879-2893. [CrossRef]

37. Paul, S.K. Supplier selection for managing supply risks in supply chain: A fuzzy approach. Int. J. Adv. Manuf. Technol. 2015, 79, 657-664. [CrossRef]

38. Bottani, E.; Rizzi, A. An adapted multi-criteria approach to suppliers and products selection-An application oriented to lead-time reduction. Int. J. Prod. Econ. 2008, 111, 763-781. [CrossRef]

39. Şahin, Y.; Supçiller, A.A. Tedarikçi Seçimi için bir Karar Destek Sistemi (A Decision Support System for Supplier Selection). Suleyman Demirel Univ. J. Eng. Sci. Des. 2015, 3, 91-104.

40. Rezaei, J.; Wang, J.; Tavasszy, L. Linking supplier development to supplier segmentation using Best Worst Method. Expert Syst. Appl. 2015, 42, 9152-9164. [CrossRef]

41. Jain, A.K. Data clustering: 50 years beyond K-means. Pattern Recognit. Lett. 2010, 31, 651-666. [CrossRef]

42. Linoff, G.S.; Berry, M.J.A. Data Mining Techniques: For Marketing, Sales, and Customer Relationship Management, 3rd ed.; Wiley: Hoboken, NJ, USA, 2011; ISBN 978-0-470-65093-6.

43. Yazici, İ.; Beyca, Ö.F.; Zaim, S. Clustering Techniques Within Service Sector. In Applying Predictive Analytics within the Service Sector; Sahu, R., Dash, M., Kumar, A., Eds.; IGI Global: Hershey, PA, USA, 2017; pp. $74-87$. [CrossRef]

44. Che, Z.H. Clustering and selecting suppliers based on simulated annealing algorithms. Comput. Math. Appl. 2012, 63, 228-238. [CrossRef]

45. Rezaei, J.; Ortt, R. Multi-criteria supplier segmentation using a fuzzy preference relations based AHP. Eur. J. Oper. Res. 2013, 225, 75-84. [CrossRef]

46. Matook, S.; Lasch, R.; Tamaschke, R. Supplier development with benchmarking as part of a comprehensive supplier risk management framework. Int. J. Oper. Prod. Manag. 2009, 29, 241-267. [CrossRef]

47. Rezaei, J.; Nispeling, T.; Sarkis, J.; Tavasszy, L. A supplier selection life cycle approach integrating traditional and environmental criteria using the best worst method. J. Clean. Prod. 2016, 135, 577-588. [CrossRef]

48. Garcia, N.; Puente, J.; Fernandez, I.; Priore, P. Supplier selection model for commodities procurement. Optimised assessment using a fuzzy decision support system. Appl. Soft Comput. 2013, 13, 1939-1951. [CrossRef]

49. Ho, W.; Xu, X.; Dey, P.K. Multi-criteria decision making approaches for supplier evaluation and selection: A literature review. Eur. J. Oper. Res. 2010, 202, 16-24. [CrossRef]

50. Punniyamoorthy, M.; Mathiyalagan, P.; Parthiban, P. A strategic model using structural equation modeling and fuzzy logic in supplier selection. Expert Syst. Appl. 2011, 38, 458-474. [CrossRef]

51. Sawik, T. Supplier selection in make-to-order environment with risks. Math. Comput. Model. 2011, 53, 1670-1679. [CrossRef]

52. Hong, Z.; Lee, C. A decision support system for procurement risk management in the presence of spot market. Decis. Support Syst. 2013, 55, 67-78. [CrossRef]

53. Knemeyer, A.; Zinn, W.; Eroglu, C. Proactive planning for catastrophic events in supply chains. J. Oper. Manag. 2009, 27, 141-153. [CrossRef]

54. Xiao, Z.; Chen, W.; Li, L. An integrated FCM and fuzzy soft set for supplier selection problem based on risk evaluation. Appl. Math. Model. 2012, 36, 1444-1454. [CrossRef]

55. Chan, F.T.S.; Kumar, N. Global supplier development considering risk factors using fuzzy extended AHP-based approach. Omega 2007, 35, 417-431. [CrossRef]

56. Thanaraksakul, W.; Phruksaphanrat, B. Supplier Evaluation Framework Based on Balanced Scorecard with Integrated Corporate Social Responsibility Perspective. In Proceedings of the International MultiConference of Engineers and Computer Scientists, IMECS 2009, Hong Kong, China, 18-20 March 2009; Volume II.

57. Chou, S.Y.; Chang, Y.H. A decision support system for supplier selection based on a strategy-aligned fuzzy SMART approach. Expert Syst. Appl. 2008, 34, 2241-2253. [CrossRef]

58. Wang, T.K.; Zhang, Q.; Chong, H.Y.; Wang, X. Integrated Supplier Selection Framework in a Resilient Construction Supply Chain: An Approach via Analytic Hierarchy Process (AHP) and Grey Relational Analysis (GRA). Sustainability 2017, 9, 289. [CrossRef] 
59. Er Kara, M.; Oktay Fırat, S.Ü. Sustainability, Risk, and Business Intelligence in Supply Chains. In Handbook of Research on Green Economic Development Initiatives and Strategies; Erdoğdu, M., Arun, T., Ahmad, I., Eds.; IGI Global: Hershey, PA, USA, 2016.

60. Sawik, T. Joint supplier selection and scheduling of customer orders under disruption risks: Single vs. dual sourcing. Omega 2014, 43, 83-95. [CrossRef]

61. Lee, S.H. Determining the Optimal Number of Cluster Suppliers under Supply Failure Risks. Int. J. Supply Chain Manag. 2014, 3, 16-23.

62. Amorim, P.; Curcio, E.; Almada-Lobo, B.; Barbosa-Póvoa, A.P.F.D.; Grossmann, I.E. Supplier selection in the processed food industry under uncertainty. Eur. J. Oper. Res. 2016, 252, 801-814. [CrossRef]

63. Wu, D.; Olson, D.L. Supply chain risk, simulation, and vendor selection. Int. J. Prod. Econ. 2008, 114, $646-655$. [CrossRef]

64. Schoenherr, T.; Tummala, V.M.R.; Harrison, T.P. Assessing supply chain risks with the analytic hierarchy process: Providing decision support for the offshoring decision by a US manufacturing company. J. Purch. Supply Manag. 2008, 14, 100-111. [CrossRef]

65. Rezaei, J. Best-worst multi-criteria decision making method: Some properties and a linear model. Omega 2016, 64, 126-130. [CrossRef]

66. Kar, A.; Pani, A. How can a group of procurement experts select suppliers? An approach for group decision support. J. Enterp. Inf. Manag. 2014, 27, 337-357. [CrossRef]

67. Awasthi, A.; Govindan, K.; Gold, S. Multi-tier sustainable global supplier selection using a fuzzy AHP-VIKOR based approach. Int. J. Prod. Econ. 2018, 195, 106-117. [CrossRef]

68. Mokhtar, S.; Bahri, P.A.; Moayer, S.; James, A. A Novel Decision-Making Approach for Supplier Selection under Risks. In 27th European Symposium on Computer Aided Process Engineering; Espuña, A., Graells, M., Puigjaner, L., Eds.; Computer Aided Chemical Engineering; Elsevier: Amsterdam, The Netherlands, 2017; Volume 40, pp. 1267-1272. [CrossRef]

69. Kannan, V.R.; Tan, K.C. Supplier Selection and Assessment: Their Impact on Business Performance. J. Supply Chain Manag. 2002, 38, 11-21. [CrossRef]

70. Guertler, B.; Spinler, S. Supply risk interrelationships and the derivation of key supply risk indicators. Technol. Forecast. Soc. Chang. 2015, 92, 224-236. [CrossRef]

71. Cheraghi, S.H.; Dadashzadeh, M.; Subramanian, M. Critical Success Factors for Supplier Selection: An Update. J. Appl. Bus. Res. 2004, 20, 91-108. [CrossRef]

72. Saaty, T.L. Decision making with the analytic hierarchy process. Int. J. Serv. Sci. 2008, 1, 83-98. [CrossRef]

73. Malhotra, N.K. Marketing Research: An Applied Orientation, 6th ed. Pearson Higher Ed USA. 2009. Available online: http:/ / www.pearson.com.au/products/M-N-Malhotra/Marketing-Research-AnApplied-Orientation-Global-Edition/9780136094234?R=9780136094234 (accessed on 30 March 2018).

74. Hair, J.F.; Black, W.C.; Babin, B.J.; Anderson, R.E. Multivariate Data Analysis, 7th ed.; Pearson Prentice Hall: Upper Saddle River, NJ, USA, 2009; ISBN 978-0138132637.

75. Warner, R.M. Applied Statistics: From Bivariate Through Multivariate Techniques, 2nd ed.; SAGE Publications: Thousand Oaks, CA, USA, 2012; ISBN 978-1412991346.

76. Piegorsch, W.W. Statistical Data Analytics: Foundations for Data Mining, Informatics, and Knowledge Discovery; Wiley: Hoboken, NJ, USA, 2015; ISBN 978-1118619650.

(C) 2018 by the authors. Licensee MDPI, Basel, Switzerland. This article is an open access article distributed under the terms and conditions of the Creative Commons Attribution (CC BY) license (http://creativecommons.org/licenses/by/4.0/). 